\title{
Current conservation status of the Blue Swallow Hirundo atrocaerulea Sundevall 1850 in Africa
}

\author{
Steven W Evans ${ }^{1 *}$, Ara Monadjem², Lizanne Roxburgh',4, Andrew E McKechnie ${ }^{5}$, Ellizabeth M Baker ${ }^{6}$, Robert \\ B Kizungu ${ }^{7}$, Ian T Little ${ }^{4}$, Fadzai Matsvimbo ${ }^{8}$, Ronald K Mulwa ${ }^{9}$, Daniel Mwizabi ${ }^{10}$, Dianah Nalwanga ${ }^{11}$, \\ Kariuki Ndang'ang'a ${ }^{12}$ and Leigh Combrink ${ }^{4}$
}

\author{
1 SARCHI Chair on Biodiversity Value and Change, School of Mathematical and Natural Sciences, University of Venda, \\ Thohoyandou, South Africa; and Unit for Environmental Sciences and Management, North-West University, Potchefstroom \\ Campus, Potchefstroom, South Africa \\ 2 Department of Biological Sciences, University of Swaziland, Kwaluseni, Swaziland; and Mammal Research Institute, \\ University of Pretoria, Pretoria, South Africa \\ ${ }^{3}$ Percy FitzPatrick Institute of African Ornithology, DST-NRF Centre of Excellence, University of Cape Town, Cape Town, \\ South Africa \\ ${ }^{4}$ Endangered Wildlife Trust, Modderfontein, South Africa \\ ${ }^{5}$ Percy FitzPatrick Institute of African Ornithology, DST-NRF Centre of Excellence, Department of Zoology and Entomology, \\ University of Pretoria, Pretoria, South Africa \\ 6 Tanzanian Bird Atlas Project, Iringa, United Republic of Tanzania \\ 7 Organisation of Biodiversity Information and Conservation in Congo Kinshasa, Kinshasa, Democratic Republic of Congo \\ ${ }^{8}$ BirdLife Zimbabwe, Harare, Zimbabwe \\ ${ }^{9}$ National Museums of Kenya and Nature Kenya, Nairobi, Kenya \\ 10 Zambian Wildlife Authority, Lusaka, Zambia \\ 11 Nature Uganda, Kampala, Uganda \\ 12 BirdLife International, Africa Partnership Secretariat, Nairobi, Kenya \\ * Corresponding author, e-mail: steven.univen@vodamail.co.za
}

\begin{abstract}
The global Blue Swallow Hirundo atrocaerulea was classified as Vulnerable in $\mathbf{2 0 1 0}$ on account of its small and rapidly declining population estimated at less than 1500 pairs. We undertook this study to gain a better understanding of the current status and threats facing this migratory species. Three previously unknown areas that might be part of the species' non-breeding range were identified in Kenya and northern Tanzania. Within its breeding range we identified three previously unknown areas of potentially suitable habitat, one in Tanzania and two in Malawi, which require further exploration. Population viability assessment predicted that the Blue Swallow population will decline by $8 \%$ in 10 years. The overall probability of extinction of the species in the wild is $3 \%$. Minimum viable population size analysis suggests that a goal for the long-term conservation of the Blue Swallow should be to mitigate current threats that are driving declines such that the population increases to a minimum of 3600 individuals. This should consist of at least 900 individuals in each of the four clusters identified, along with a minimum of 500 individuals in at least one of the meta-populations per cluster. The four clusters are located in (1) the southeasten Democratic Republic of the Congo, (2) highlands of southern Tanzania and northern Malawi, (3) eastern highlands of Zimbabwe and (4) South Africa and Swaziland. The current proportions of the Blue Swallow population in strictly protected and unprotected areas on their breeding grounds are $53 \%$ and $47 \%$, respectively, whereas on their non-breeding grounds the corresponding percentages are $25 \%$ and $75 \%$, respectively. Our reassessment of the Blue Swallow's risk of extinction indicates that it continues to qualify as Vulnerable according to the IUCN/SSC criteria C2a(i).
\end{abstract}

Keywords: Blue Swallow, conservation recommendations, conservation status, distribution, Hirundinidae, minimum viable population size, population viability, species distribution modelling, threats

Introduction

The text of the Convention on the Conservation of Migratory Species of Wild Animals (CMS) states that the conservation and effective management of migratory wild animals requires the concerted action of all range states within whose national jurisdictional boundaries such species spend any part of their life cycle (CMS 2003). A globally threatened migratory species that spends different parts of its life-cycle in different regions and countries 
can only be conserved if all of the countries cooperate towards conserving the species concerned. The Blue Swallow Hirundo atrocaerulea is a prime example of a globally threatened migratory species requiring the cooperation of all 10 range states in order to conserve it and its unique grassland and wetland habitat (Evans et al. 2002). This study was undertaken to gain a better understanding of the current status and vulnerability of the Blue Swallow throughout its range. In order to achieve this, species distribution modelling (SDM) and population viability analysis (PVA) techniques were used. In addition, the minimum viable population size (MVP) for the Blue Swallow was estimated.

MaxEnt is one of many programs used for SDMs (Elith and Leathwick 2009). SDMs can be defined as associative models relating occurrence or abundance data at known locations of individual species to information on the environmental characteristics of those locations in order to predict where else the species may occur and were it is unlikely to occur (Elith and Leathwick 2009; Cassini 2011). SDMs can seldom be developed using all the environmental and resource requirements of a species and consequently rely on a sample of characteristics (e.g. climate) as a suitable proxy (Elith and Leathwick 2009). In addition, relatively few occurrence data are available and may encompass only a portion of the geographic range of the species (sampling bias) (Fitzpatrick et al. 2013). Despite these aforementioned limitations, SDMs have been used to predict the known and potential distributions of threatened species (Beaumont et al. 2005), predict potential global invasions of plants (Thuiller et al. 2005) and animals (DeMeyer et al. 2008) outside of their native range, and to determine the potential impacts of climate change on the distribution of threatened species such as the Sokoke Scops Owl Otus ireneae (Monadjem et al. 2013).

The second approach we use here, PVA, assesses a species' likelihood of persisting over an accepted period of time into the future and the conservation measures needed to prevent its extinction (Boyce 1992; Pianka 2000). PVAs, such as for Bonnelli's Eagle Hieraaetus fasciatus, are based on species' demographic parameters (e.g. sex ratio, birth rate and death rate) (Pianka 2000). Closely related to PVAs are MVP analyses (Boyce 1992). A MVP analysis estimates the lowest number of individuals at which the probability of that species going extinct from stochastic events, over a specified period of time, is minimised (Pianka 2000). The quality of PVAs and MVPs are affected by the ecology of the species concerned, the experience of the modellers involved, and the extent of data available for the species (Boyce 1992). However, when combined with an adaptive management approach, both PVA and MVP models are useful tools that contribute to the conservation of threatened species (Boyce 1992).

The Blue Swallow is globally classified as Vulnerable due to its small and rapidly declining population, estimated at less than 1500 pairs, resulting from rapid reductions in the quantity and quality of its unique grassland and wetland habitat (BirdLife International 2000; Evans and Bouwman 2010a; BirdLife International 2012). The East African (Uganda, Kenya and Tanzania) population was classified as Endangered under East African regional Red Data criteria (Bennun and Njoroge 1996). The South African and Swaziland populations were both classified as Critically Endangered (Evans and Barnes 2000; Monadjem et al. 2003; Evans in press).

The Blue Swallow migrates between its breeding grounds in eastern South Africa, north-western Swaziland, eastern Zimbabwe, western Mozambique, Malawi, north-eastern Zambia, southern Tanzania and south-eastern Democratic Republic of the Congo (DRC), and its non-breeding grounds in western Kenya, southern Uganda, north-western Tanzania and the north-eastern DRC (Turner and Rose 1989; Keith et al. 1992; Evans and Bouwman 2010a). The birds occupy their breeding grounds from late September to mid-April (c. seven months) and their non-breeding grounds from late April to late August or early September (c. five months) (Keith et al. 1992). The seven migratory routes believed to be used by the birds between their breeding and non-breeding grounds and back are (1) South Africa and Swaziland to south-western Uganda (Evans and Bouwman 2010a; Wakelin et al. 2011), (2) Zimbabwe to south-western Uganda (Evans and Bouwman 2010a), (3 and 4) southwestern Malawi, northern Malawi and south-western Tanzania to south-western Uganda (Evans and Bouwman 2010a), (5 and 6) south-eastern Malawi to western Kenya and south-eastern Uganda (Evans and Bouwman 2010a) and (7) south-eastern DRC to north-eastern DRC (Evans and Bouwman 2010a). Changes in habitat quantity and quality in the breeding and non-breeding ranges, as well as along the migratory routes, have been identified as major factors driving the recent reduction in numbers (Evans and Bouwman 2010a).

On their breeding grounds Blue Swallows prefer a mosaic of grasslands for nesting, and wetlands such as drainage lines for foraging (Evans and Bouwman 2010b). On their breeding grounds sufficient foraging habitat must be within a $1.5 \mathrm{~km}$ radius of an active nest site (Evans and Bouwman 2010b). On their non-breeding grounds in Uganda the birds roost and forage over seasonally flooded wetlands, during the dry season, adjacent to Lake Victoria (Evans 2008). On their non-breeding grounds in Kenya the habitat is similar to that used by the birds on their breeding grounds as it consists of a mosaic of grasslands and wetlands (Ndang'ang'a 2007). In Kenya, the birds roost over and forage near to wetlands. The non-breeding habitat in the $\mathrm{DRC}$ is presumed to be similar to that in Kenya.

The Blue Swallow is threatened throughout its range by a wide variety of anthropogenic pressures. These include habitat degradation and conversion due to commercial afforestation, invasion of exotic eucalyptus, pine and wattle trees (Childes 2001), large-scale agriculture, rural population growth, mining, urbanisation and permanent removal of livestock and/or large ungulates (Parker 1994; Evans et al. 2002, 2003; Monadjem et al. 2003; Mwizabi et al. 2003; BirdLife Zimbabwe 2004; Ndang'ang'a 2007; Wakelin and Hill 2007; Evans 2008; Combrink and Little 2012). Moreover, air pollution may result in Blue Swallow's feathers becoming waterlogged, adversely affecting the birds' ability to forage (Kylin et al. 2011). The implementation of sustained conservation efforts for the Blue Swallow has also been severely hampered by political conflict in the DRC (Evans et al. 2002). In coming decades, climate change might result in 
a contraction of the Blue Swallow's range in South Africa by as much as $30 \%$ by 2050 (Simmons et al. 2005). Although the latter study focused on southern Africa only, changes may be expected in other parts of the Blue Swallow breeding range. BirdLife International and Durham University (2013) used grossly inaccurate information on the present-day distribution of the Blue Swallow in their study on the impacts of climate change on this species. Consequently, their predictions of the effects of climate change and its effects on the future distribution of the Blue Swallow in eastern and southern Africa are of limited use (BirdLife International and Durham University 2013).

With regards to the Blue Swallow, the five objectives of this study were to (1) update knowledge regarding the current breeding and non-breeding range; (2) model the distribution of the species using nest and site records to determine potential gaps in our knowledge of the species distribution; (3) complete an assessment of the viability of the population throughout its range and determine the minimum viable population size required to conserve the species; (4) determine what proportion of the population is in strictly protected areas and identify areas in need of conservation based on the distribution of the unprotected proportion of the population; and (5) evaluate the species' current conservation status according to the IUCN/SSC (2012) criteria.

\section{Methods}

\section{Terminology}

Metapopulations refer to two or more geographically discrete areas occupied by the birds and in which there is some exchange of individuals and genes between the discrete geographic areas. Subpopulations refer to two or more geographically discrete areas occupied by the birds and in which there is no exchange of individuals between the discrete geographic areas (IUCN/SSC 2012). Throughout the text the terms metapopulation and subpopulation have been used according to these definitions. An exception is that when Blue Swallows are referred to collectively in a number of discrete geographic areas consisting of both meta- and sub-populations, the default has been to use subpopulation, as there is no term for this, and there was a need to be sure the reader understood that the entire Blue Swallow population was not being referred to.

Current distribution, demographics, current extent of protection, and gaps in the Important Bird Area network The historic (1850s) extent of occurrence of Blue Swallows per quarter degree grid cell (QDGC) was taken from Evans and Bouwman (2010a). Development of the maps of the distribution range of the Blue Swallow is described in Evans and Bouwman (2010a). In order to display the current distribution range of the Blue Swallow, recent information (late 2010 to 2012) was used to update the maps. Sources include Baker and Baker (2009, 2012), Combrink and Little (2012), Evans et al. (in press), sightings of Blue Swallows reported on list-servers for Kenya (e.g. C Onyi pers. comm., 2011) or Tanzania (e.g. AS Kennedy, pers. comm., 2012) and the authors' personal knowledge of the birds. Current knowledge was used to update the figures initially presented by Evans and Bouwman (2010a) of the estimated Blue Swallow numbers and proportions that are protected (formally protected areas), partially protected (Ramsar sites, natural heritage sites and forest reserves) and unprotected throughout their breeding and non-breeding ranges.

Blue Swallows recorded in September to April and within their known breeding distribution range were considered to be on their breeding grounds. If recorded in April to September and within their known non-breeding distribution range, they were considered to be on their non-breeding grounds. Birds recorded in April and May and outside of their known breeding range were considered to be on migration north to their non-breeding grounds. Birds recorded in September and October and outside of their known non-breeding range where considered to be on migration south to their breeding grounds.

An assessment of changes to breeding and non-breeding Blue Swallow metapopulations in currently recognised Important Bird Areas (IBAs) was undertaken. In addition, recommendations are made on areas that should be selected as IBAs if the presence of Blue Swallows in these areas is confirmed. The present study makes recommendations on the selection of IBAs based on updated information on the Blue Swallows breeding and non-breeding range.

\section{Modelled distribution using MaxEnt}

The advantage of using MaxEnt is that it has been shown to perform well when compared with other similar methods, such as BIOCLIM and GLM (Phillips et al. 2004; Gibson et al. 2007; Pearson et al. 2007; Hernandez et al. 2008; Stabach et al. 2009), even when dealing with a small number of occurrence records (Hernandez et al. 2006; Pearson et al. 2007; Wisz et al. 2008). In addition, MaxEnt uses presence-only records of a species along with bioclimatic and other variables of a species environment in order to determine if there are other areas with a similar bioclimatic and/or range of environmental variables and consequently where else the species might occur (Elith et al. 2011). For a detailed statistical and technical discussion of MaxEnt, see Phillips et al. (2006), Phillips and Dudík (2008) and Elith et al. (2011).

Georeferenced sight $(n=177)$ and nest $(n=232)$ records of Blue Swallows were used to model their potential breeding distribution range (MaxEnt 3.3.3e). The sight records were from Tanzania, Malawi and Zimbabwe. The nest records were from South Africa, Swaziland and Malawi. Eight continuous bioclimatic variables (spatial resolution of $90 \mathrm{~m}$ ), obtained from WorldClim (Hijmans et al. 2005; http://www.worldclim.org), and five categorical variables were included as predictors in the model (Supplementary Table S1). Human-induced changes to the landscape were not excluded from the maps of the birds' modelled distribution. Insufficient data were available to model the non-breeding distribution range.

The MaxEnt model was run with $75 \%$ training and $25 \%$ random test data, and the regularisation multiplier was set to 1 (Lamb et al. 2008). All other MaxEnt settings were set on default. Model performance was evaluated by examining the area under the receiver operating characteristic curve (AUC), and by a jackknife test that examines the importance of each environmental variable, first by 
removing one variable at a time and then each variable in isolation (Phillips et al. 2006).

The current known Blue Swallow breeding distribution range (based on QDGCs) was compared with the results of the modelled breeding distribution range of the birds. This comparison was used to determine if there are any Blue Swallow breeding areas and metapopulations that may previously have been overlooked.

\section{Population viability and minimum viable population size} Vortex is an individual-based simulation model for PVA (Miller and Lacy 2005). Vortex was initially written to model mammalian and avian populations by going through a series of events describing the typical life cycle of these sexually reproducing, diploid animals (Lacy et al. 2005; Miller and Lacy 2005).

The viability of the Blue Swallow population, for the period 2005-2105, throughout its breeding range was assessed using Vortex 9.99b. Metapopulations known to have declined or become locally extinct since 2005 (Supplementary Table S2) were compared with the predictions of the model as a means of determining the validity of the models predictions and its usefulness. The results presented are the means of 1000 iterations of each model.

There are many uncertainties in the variables used in the model due to an absence of information specific to the Blue Swallow and most of its metapopulations. Consequently, a baseline model was constructed to represent a conservative scenario for the Blue Swallow. This was done for two primary reasons: (1) such a model should avoid being over-optimistic about the species' viability and thereby avoid misleading conservationists, and (2) it should provide a more accurate indication of the minimum requirements needed to conserve the Blue Swallow, thereby providing information useful to conservationists.

The baseline model was used to conduct sensitivity analyses of variables (e.g. first-year mortality) for which information specific to the Blue Swallow was not available. Each sensitivity analysis determines whether a change in the value estimated for a given variable results in a change to the predictions of the model (e.g. risk of extinction) compared with the predictions of the baseline model. This is used to assess whether variables for which information specific to the Blue Swallow was not available might affect the usefulness of the predictions of the baseline model. It is also used to make recommendations on research needed to reduce the number of unknown variables aimed at improving the model, its predictions and its usefulness.

\section{Baseline model}

No data specific to each of the 20 Blue Swallow metapopulations were available for certain variables. Where data were available for certain variables from a subset of metapopulations, the mean values of these variables were used as the starting point for all 20 Blue Swallow metapopulations included in the model (Figure 1, Supplementary Table S2).

Size, dispersal between and designation of metapopulations The Blue Swallow population is not distributed continuously throughout its breeding range due to the highly fragmented nature of its grassland and wetland habitat (Evans and
Bouwman 2010a). All breeding areas that were further than $50 \mathrm{~km}$ from each other were treated as separate metapopulations (Figure 1). Dispersal was set to $1 \%$ (the minimum possible) of a metapopulation dispersing annually to the nearest metapopulation to its north and south, irrespective of the distance between them.

Current information (Evans et al. in press) suggests that Evans and Bouwman's (2010a) estimate of 160 pairs of Blue Swallows underestimated the number of breeding Blue Swallows in south-western Tanzania by approximately 228 pairs or $59 \%$. Consequently, in 2005, throughout their breeding range, there could have been as many as 1264 pairs of Blue Swallows (Supplementary Table S2). The viability of the Blue Swallow population in Africa was assessed assuming a minimum of 388 pairs in the southern highlands of Tanzania (Supplementary Table S2).

No surveys of Blue Swallows in the Marungu Highlands or Upemba National Park have been carried out (Figure 1a). No information is available on the extent of suitable habitat for Blue Swallows in the Marungu Highlands or Upemba National Park. It is possible that the 50 pairs estimated for each of these two areas in the DRC (Evans and Bouwman 2010a) are also an underestimation (Figure 1, Supplementary Table S2). However, due to a lack of current information, viability was assessed assuming 50 pairs for each of these two areas, in favour of the alternative of not including these two areas in the assessment (Supplementary Table S2).

\section{Carrying capacity}

The initial size of each metapopulation (Supplementary Table S2) and carrying capacity were modelled as being the same. Due to an absence of data for each metapopulation and the probability that the rate of habitat loss differs greatly between metapopulations and countries, carrying capacity was modelled as remaining unchanged. Any change in the variables describing each metapopulation (e.g. intrinsic rate of natural increase in population size, and probability of extinction) will therefore not be due to a change in carrying capacity. Due to an absence of data specific to the Blue Swallow, or any other birds, the effects of inbreeding depression were not included in any of the models. Extinction was modelled as one bird remaining.

\section{Age of first reproduction}

The age at which male and female Blue Swallows are capable of producing offspring was modelled as being at one year, which is typical for hirundines (Turner and Rose 1989). Transect counts $(n=42)$ of the number of males and females in the Blue Swallow Natural Heritage Site produced a mean of 12.1 adult males, which was not significantly more (Mann-Whitney test, unpaired, two-tailed, $P>0.05$ ) than the mean of 9.8 adult females (Evans 2008). Consequently, adults and nestlings were modelled as having an equal sex ratio. All females were assumed to attempt breeding.

\section{Longevity}

Blue Swallow longevity is unknown. Hirundines, on average, breed for only one or a few seasons before dying (Turner and Rose 1989). Most Barn Swallows Hirundo 


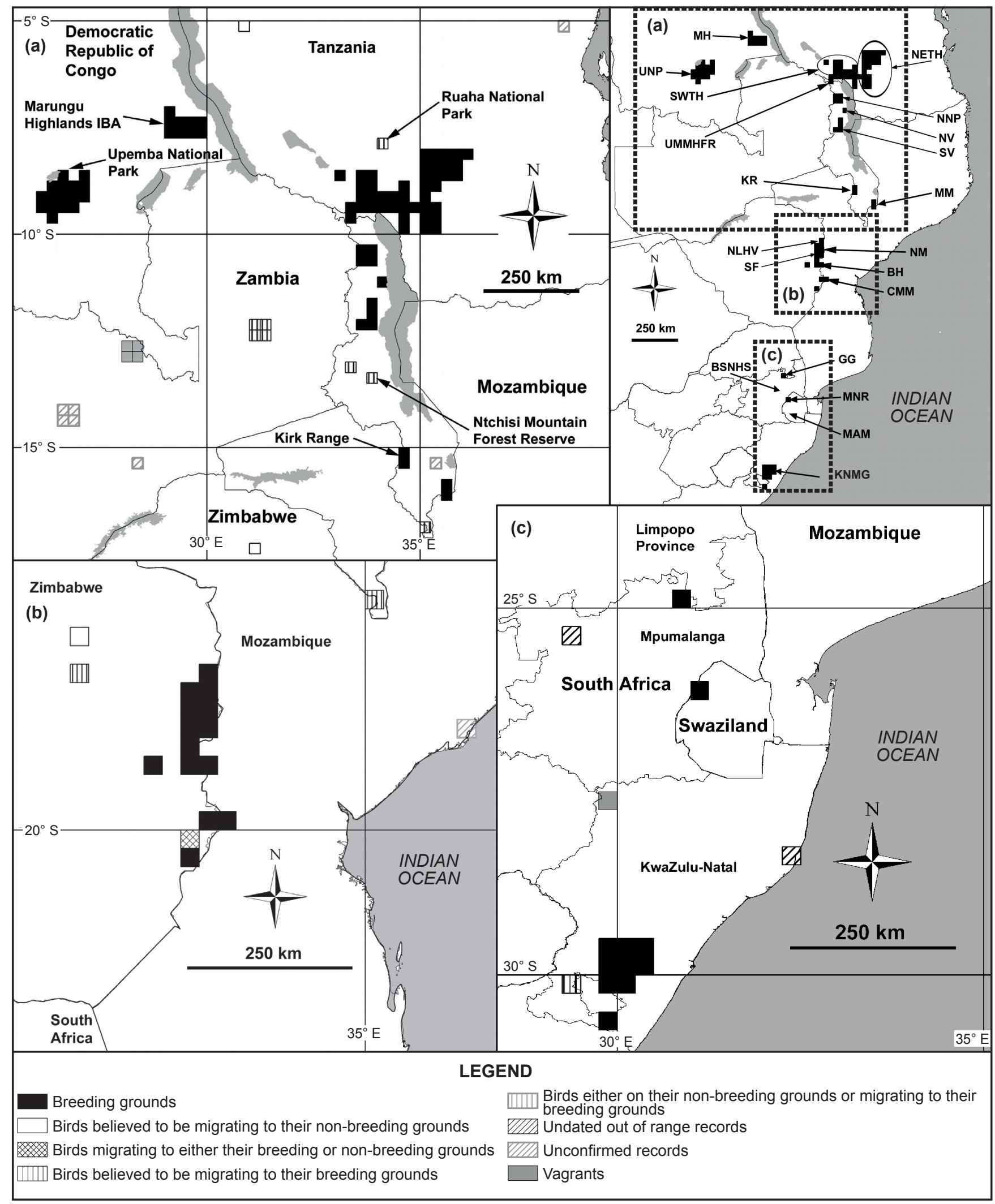

Figure 1: Approximate position of each of the 20 Blue Swallow meta-populations used to assess the viability of the Blue Swallow population throughout its entire breeding range (see also Supplementary Table S2). The current breeding distribution range of the Blue Swallow in the north (a), centre (b) and south (c) of its range is shown 
rustica live fewer than four years (Rydzewski 1978). The Common House Martin Delichon urbica typically breeds for only one year, but a few individuals may continue breeding for five or six years, rarely surviving longer than this (Bryant 1975; Rydzewski 1978). Hence, the longevity of hirundines ranges from approximately one to six years (Bryant 1975; Rydzewski 1978; Turner and Rose 1989). Blue Swallow breeding longevity was modelled as four years, which is two-thirds of the longevity range presented above for other hirundines.

\section{Mortality}

The mean annual mortality of Barn Swallows was $40-70 \%$ for adults and $70-80 \%$ for first-year birds (Cramp 1988). First-year Sand Martins had a mortality rate of $77 \%$ and older birds $60 \%$ (Mead 1979). The annual mortality rate of adult Wire-tailed Swallows in Malawi was 36\% (Peach et al. 2001). Mortality rates for adult and first-year migratory birds ranged from $12 \%$ to $70 \%$ and $29 \%$ to $80 \%$, respectively (Perrins 1971; Beklova 1976; Mead 1979; Cramp 1988). In the absence of data specific to Blue Swallows these mortality rates for other hirundines were used to estimate mortality rates for Blue Swallows. Mortality of first-year birds was modelled as $65 \%(S D=15)$, which is nearer the upper extreme, and mortality of adult Blue Swallows was modelled as $40 \%(S D=15)$.

\section{Proportion of males siring offspring}

The male Blue Swallow has two long outer tail feathers, forming streamers, which are observably shorter in the female (Keith et al. 1992). Although the difference in the length of their outer tail feathers is not as great, Barn Swallow females select males based on the length and symmetry of their outer tail feathers (Møller 1988). Male Barn Swallows with the longest and symmetrical outer tail feathers will acquire a female and breed earlier in the season and produce two broods more regularly than males with shorter and/or asymmetrical outer tail feathers (Møller 1988). Furthermore, male Barn Swallows with the longest outer tail feathers will mate with further females (extra-pair copulations) and sire offspring that will be raised by other males (males with shorter outer tail feathers) (Møller 1984, 1988). Consequently, approximately one-third of males within a population contribute to the gene pool and there is competition between males to acquire a female and successfully breed (Møller 1988). Sexual selection amongst Blue Swallows may be similar to that of Barn Swallows. Consequently, Blue Swallows were modelled as being polygamous with only $35 \%$ of males successfully siring offspring. This means that some males may only successfully sire offspring in years two or later with some never siring offspring.

\section{Number of broods per pair per season}

In Zimbabwe, Swaziland and South Africa a very small proportion $(<3 \%)$ of Blue Swallow pairs $(n=249$ nesting attempts, 30 breeding seasons between 1900/01 and $2000 / 01$ ) produce three broods or undertake three breeding attempts in a season (Evans 2008). The term 'breeding attempt' refers to birds breeding successfully a second and third time as well as to replacement clutches or broods due to the loss of the first or second clutches or broods (Evans 2008). As the incidence of Blue Swallows producing three broods or breeding attempts in a season was very low (Evans 2008), the maximum number of broods was modelled at two per pair per season with a maximum of three fledglings per brood, for all 20 metapopulations. The proportion of pairs producing one and two broods in a season was modelled as being $60 \%$ and $40 \%$, respectively, for all 20 metapopulations (Evans 2008). The proportion of broods successfully fledging one, two and three nestlings were modelled as being $15 \%$, $40 \%$ and $45 \%$, respectively, for all 20 metapopulations (Evans 2008).

\section{Sensitivity and conservativeness of the model}

First-year mortality, breeding longevity and annual adult mortality are not known for the Blue Swallow. Consequently, the sensitivity of the predictions of the baseline model to changes to these three variables was tested (Supplementary Figure S3). In addition, predictions of the baseline model to a decline in carrying capacity (decline in extent of occurrence) of all metapopulations that are not in strictly protected areas were determined for metapopulations in South Africa, Swaziland and Zimbabwe and modelled at a rate of decline in carrying capacity of $0.62 \%, 0.72 \%$ and $0.11 \%$ per year, respectively, and at a rate of decline of $0.19 \%$ for all remaining metapopulations. These estimates of a decline in carrying capacity are based on estimates of the decline in the Blue Swallows breeding distribution range at the scale of the QDGC. All variables used in the baseline Vortex model for the Blue Swallow are provided in Supplementary Appendix 1.

\section{Minimum viable population size}

The baseline model was used to develop an additional eight metapopulation baseline models each consisting of one to eight metapopulations. These eight models were used to determine the minimum number of individuals per metapopulation at which the population was predicted to have a $0.1-2 \%$ probability of extinction.

Populations consisting of two to eight metapopulations were modelled with $1 \%$ of individuals dispersing annually to the preceding population and with individuals from the second population dispersing to the first. For all metapopulations the initial population size and carrying capacity were modelled as being the same. Carrying capacity was modelled as remaining unchanged over 100 years.

The sensitivity of the predictions of these eight metapopulation baseline models were tested against changes to variables to which predictions of the baseline model were determined to be sensitive. These eight metapopulation baseline models were used to make conservative and liberal estimates of the number of Blue Swallow metapopulations and the number of individuals per metapopulation needed to conserve the species in the absence of a change in carrying capacity of the areas they occupy.

\section{Current conservation status}

The Blue Swallows were assessed against the IUCN criteria in order to determine their current conservation status per country (IUCN/SSC 2012). 


\section{Results}

Current distribution, demographics, current extent of protection and gaps in the IBA network

QDGCs in which places are located, and QDGCs that are located within named areas and referred to in the text, are indicated in Figures $1 \mathrm{a}-\mathrm{c}$ and 2.

\section{Recent changes in our knowledge of the Blue Swallow's breeding and non-breeding distribution range}

Uganda

In Uganda, there are no recent records of Blue Swallows in or near Mabira Forest IBA (Figure 2). Blue Swallows have probably become extinct locally in this area.

\section{Kenya}

On 13 September 2011, approximately five Blue Swallows were observed foraging along the shores of Lake Victoria near the town of Asembo in Kenya (C Onyi pers. comm., 2011). In September, birds are probably on migration south to their breeding grounds (Turner and Rose 1989). This is the first time that Blue Swallows have been recorded in this area. This area is within the range of latitudes $\left(02^{\circ} \mathrm{N}\right.$ and $01^{\circ} \mathrm{S}$ ) and longitudes (30-35 $\mathrm{E}$ ) occupied by non-breeding Blue Swallows and contains habitat that is similar to what non-breeding birds occupy in Uganda (Figure 2). The area could be a previously unknown part of the Blue Swallow's non-breeding range or an area into which the birds have recently extended their non-breeding range. This area is currently not listed as an IBA (Fishpool and Evans 2001). On 16 and 31 July 2012, Blue Swallows were observed in the Masai Mara IBA in Kenya very near the border with Tanzania (Figure 2) (AS Kennedy pers. comm., 2012). In July, Blue Swallows are expected to be on their non-breeding range (Turner and Rose 1989).

\section{Tanzania}

On 12 August 1994, a single Blue Swallow was observed in the Serengeti National Park IBA in Tanzania (Figure 2) (Zimmerman et al.1996). In August birds could either be on their non-breeding range or migrating south to their breeding grounds (Turner and Rose 1989). In September 2010 and 2011, and in August and September 2010 and 2011 Blue Swallows were recorded in Ruaha National Park and Tarangire National Park, respectively (Figure 1a) (Baker and Baker 2009, 2012). As it was

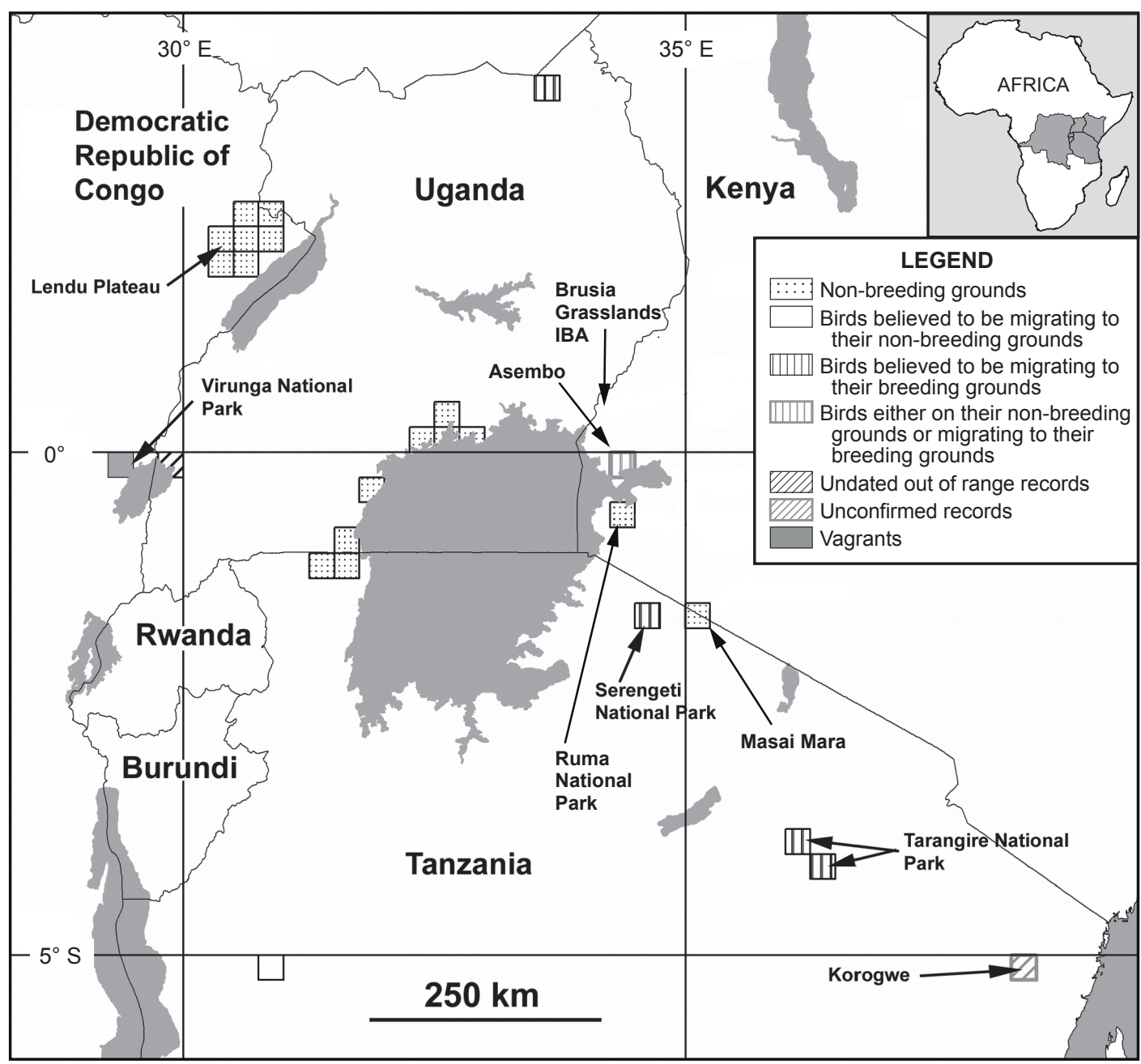

Figure 2: Current non-breeding range of the Blue Swallow 
August-September the birds were probably on migration south to their breeding range (Turner and Rose 1989).

\section{Democratic Republic of Congo}

In February 2008 a single male Blue Swallow was observed adjacent to the Virunga National Park (an IBA) in eastern DRC. This sighting was approximately $800 \mathrm{~km}$ north of the birds nearest known breeding area, the Marungu Highlands IBA (Figure 2) (RB Kizungu pers. comm., 2011). As the bird was observed in February, this suggests that it was either a breeding bird, a vagrant, or an early migrant en route to its non-breeding grounds on the Lendu Plateau approximately $300 \mathrm{~km}$ to the north of where it was observed (Figure 2). The habitat in this area is a mixture of rural villages and crop agriculture developed after afforestation (RB Kizungu pers. comm., 2011).

\section{Malawi}

In the early 1940s, Blue Swallows were recorded in the Kirk Range, with Mount Tsangano at its centre, on the border between south-western Malawi and Mozambique (Benson 1942) (Figure 3). This area is within the Blue Swallows breeding range (Figure 3 ). The habitat suitability modelling indicated that there may be a small amount of suitable habitat for Blue Swallows in this area (Figure 3). Blue Swallows have been recorded on North Viphya (Dowsett-Lemaire and Dowsett 2006). This area is within the Blue Swallows breeding range (Figure 3). The habitat suitability modelling indicated that there is suitable habitat for Blue Swallows in this area (Figure 3). North Viphya is not currently listed as an IBA (Supplementary Table S3) (Fishpool and Evans 2001). On 11 April 1992 Blue Swallows were recorded in Ntchisi Mountain Forest Reserve (an IBA) in Malawi (Figure 1a) (Dowsett-Lemaire et al. 2001; Dowsett-Lemaire 2006). As it was in April the birds were probably on migration north to their non-breeding range (Turner and Rose 1989).

\section{South Africa}

The record (February 2008) from the DRC is similar to the record of a male Blue Swallow ringed on 31 January 2009 near the town of Newcastle in north-western KwaZuluNatal, South Africa (Figure 1c). This was the first time a Blue Swallow had ever been recorded near Newcastle. January is too early for Blue Swallows to be migrating north (Turner and Rose 1989), and this is probably also an example of vagrancy. Currently, the nearest breeding Blue Swallows to Newcastle occur $210 \mathrm{~km}$ to the north-west and south-west in Malolotja Nature Reserve and southern KwaZulu-Natal, respectively (Figure 1c).

\section{Continent-wide}

At the scale of the QDGC there is currently no evidence for a decline in the extent of occurrence of the Blue Swallow breeding in the DRC, south-western Tanzania, Malawi and Zambia (Figure 1a). In contrast, its extent of occurrence in Zimbabwe, and especially South Africa and Swaziland, are in decline. Since 1850 and before commercial forestry, Blue Swallows were documented occupying 65 QDGCs in Zimbabwe, South Africa and Swaziland (Evans and Bouwman 2010a). Based on their historic (1850) and current (2012) distribution, the Blue Swallow's extent of occurrence has declined by $62 \%$, from 65 QDGCs to 25 in Zimbabwe, South Africa and Swaziland (Figure 1c). During this period the greatest decrease in the Blue Swallow's extent of occurrence of $88 \%\left(0.72 \% \mathrm{y}^{-1}\right)$ was in Swaziland, where their range declined from eight QDGCs (Evans and Bouwman 2010a) to one (Figure 1c). This decrease was closely followed by a $76 \%\left(0.62 \% \mathrm{y}^{-1}\right)$ decline in its extent of occurrence in South Africa, from 41 QDGCs to 10 (Figure 1c). Over the same time period a decrease of $13 \%$ $\left(0.11 \% \mathrm{y}^{-1}\right)$ occurred in the extent of occurrence of Blue Swallows in Zimbabwe, from 16 QDGCs to 14 (Figure 1b).

On its breeding range the extent of occurrence has declined by $23 \%$, from 138 QDGCs to 106 , over the past 122 years (1890-2012), or a $0.19 \%$ decline per year (Figures $1 \mathrm{~b}-\mathrm{c}$ and 2 ). On its non-breeding grounds there has been a decline in the extent of occurrence of $30 \%$, from 23 QDGCs to 16 , over the past 10 years (2002-2012), or a $3 \%$ decline per year (Figure 2). Over the entire distribution range the Blue Swallow's extent of occurrence has declined by $24 \%$, from 161 QDGCs to 122 , over the past 122 years (1890-2012) or a $0.2 \%$ decline per year (Figures $1 \mathrm{~b}-\mathrm{c}$ and 2). Based on these figures, the Blue Swallow's current breeding range is $85 \%$ larger than its non-breeding range (Figures $1 \mathrm{a}-\mathrm{c}$ and 2).

Historically, the Blue Swallow was probably not distributed throughout each QDGC, and the above estimates are probably an over-estimation of the birds' historic and current extent of occurrence. However, the change in extent of occurrence indicated by the above figures is useful in assessing the species' current conservation status using the IUCN/SSC (2012) criteria. In addition, the number of QDGCs occupied by Blue Swallows on their non-breeding range near Asembo and in the Masai Mara and Serengeti National Parks may have been underestimated. Consequently, the decline in extent of occurrence of the non-breeding range may be exaggerated.

\section{Current extent of protection and gaps in the IBA network}

An assessment of the extent to which Blue Swallows are protected along their migratory routes is beyond the scope of the present study. Throughout their breeding range, approximately $53 \%$ of the Blue Swallow population is in strictly protected areas and $47 \%$ in partially protected (natural heritage sites, forest reserves, unprotected Important Bird Areas and Ramsar sites) and unprotected areas (Supplementary Table S3). The situation is very different for the Blue Swallows on their non-breeding range where only an estimated $25 \%$ of the Blue Swallow population is in strictly protected areas and $75 \%$ are in partially protected or unprotected areas (Supplementary Table S4).

The 26 and 11 IBAs that were selected based, in part, on the presence of breeding and non-breeding Blue Swallow metapopulations, respectively, are listed in Supplementary Tables S3 and S4 (Fishpool and Evans 2001). On their breeding range Blue Swallows have metapopulations that are possibly stable, declining and have gone extinct locally in nine, 11 and six IBAs, respectively (Supplementary Table S3). On their non-breeding range Blue Swallows have metapopulations that appear to have expanded their range 
into two IBAs, along with local extinctions in three IBAs, and have stable and decreasing metapopulations in three and three IBAs, respectively (Supplementary Table S4).

\section{Modelled distribution using MaxEnt}

With the exception of South Africa, the modelled breeding distribution range of the Blue Swallow is very similar to the current breeding range (Figures 3-5). For South Africa the predicted breeding range is more extensive compared with the birds current breeding range (Figures 4 and 5). Comparing the Blue Swallows historic breeding distribution range in South Africa (Evans and Bouwman 2010a) with the modelled breeding distribution range shows that the model predicts that birds would occur in certain areas in which they have never been recorded. These include the Soutpansberg Mountains in the northern Limpopo province, areas in southern and western Mpumalanga, western KwaZulu-Natal along Lesotho's north-eastern border, and areas in the northern and central Eastern Cape province (Figure 5). These areas are frequented by birders and are unlikely to have extant populations.

In southern Malawi and south-western Tanzania are additional areas in which the Blue Swallows are predicted to occur but in which they have never been recorded either breeding or on migration (Figure 3). In Malawi, the areas, to the west of Mount Mulanje (Thyolo Escarpment) and north-west of the Kirk Range (Dedza and Chongoni Hills), predicted by the model to contain Blue Swallows have a maximum altitude of up to $1800 \mathrm{~m}$, below the range of over $2000 \mathrm{~m}$, on Mount Mulanje and the Nyika Plateau to the north, at which the birds are known to occur in this part of their breeding range. However, Blue Swallows have been recorded down to $1400 \mathrm{~m}$ in the southern highlands of Tanzania (EM Baker and NE Baker unpublished data; Evans et al. in press). Depending on the habitat, these two areas in Malawi might be marginally suitable for Blue Swallows (Figure 3).

In south-western Tanzania, south of the southern highlands of Tanzania, the area predicted by the model to contain Blue Swallows has a maximum altitude of up to $1600 \mathrm{~m}$. This is within the altitude range of 1400-2 $800 \mathrm{~m}$ at which Blue Swallows have been recorded in the southern highlands of Tanzania to the north (EM Baker and NE Baker unpublished data; Evans et al. in press). Depending on the habitat, this area in Tanzania might be suitable for a small number of Blue Swallows (Figure 3).

In a north-westward direction from the southern highlands of Tanzania there are a number of areas that the modelled breeding distribution range suggests are suitable for Blue Swallows (Figure 3). Apart from one unreliable record of a

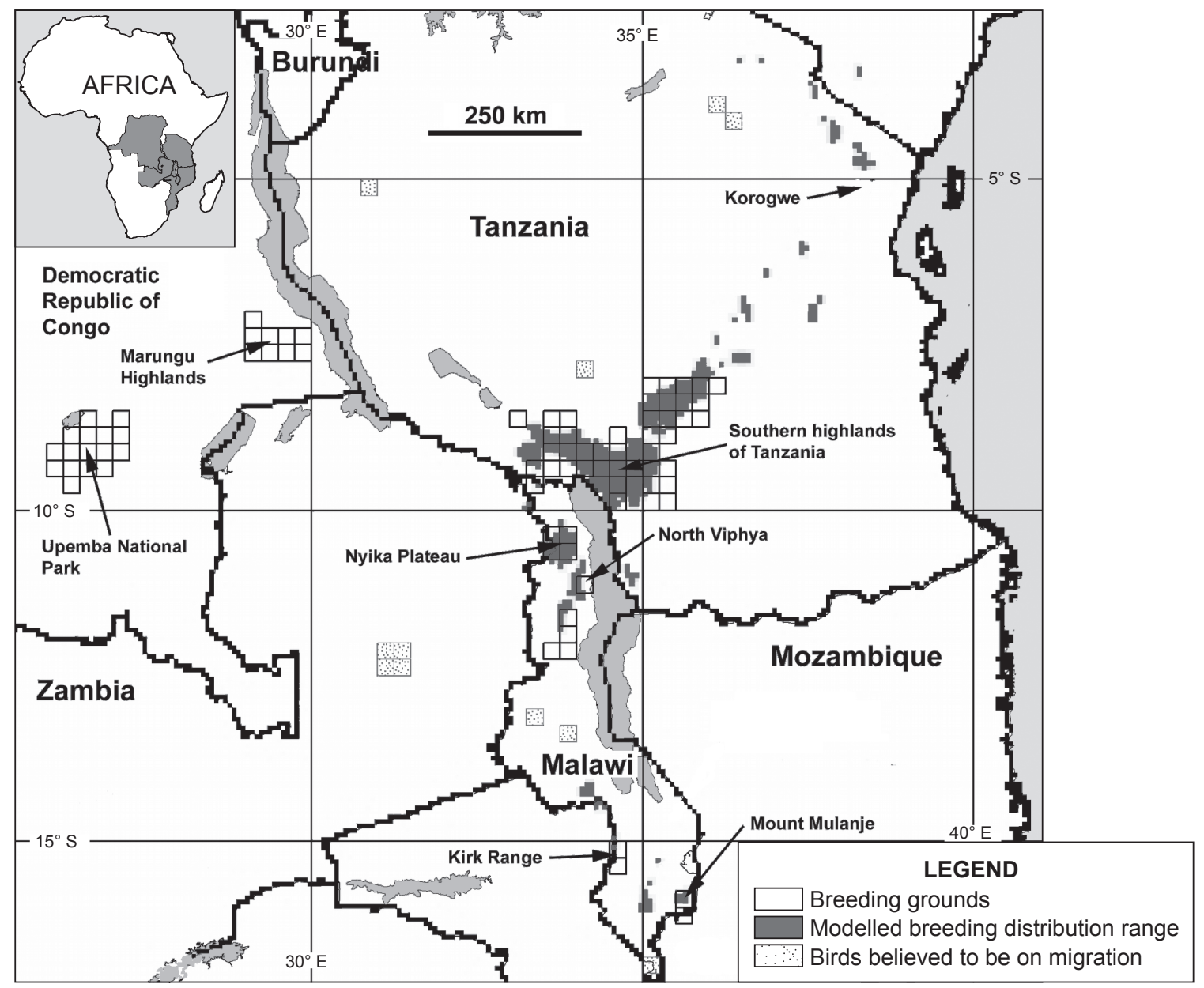

Figure 3: Modelled and current breeding distribution range of the Blue Swallow in the north of its range 


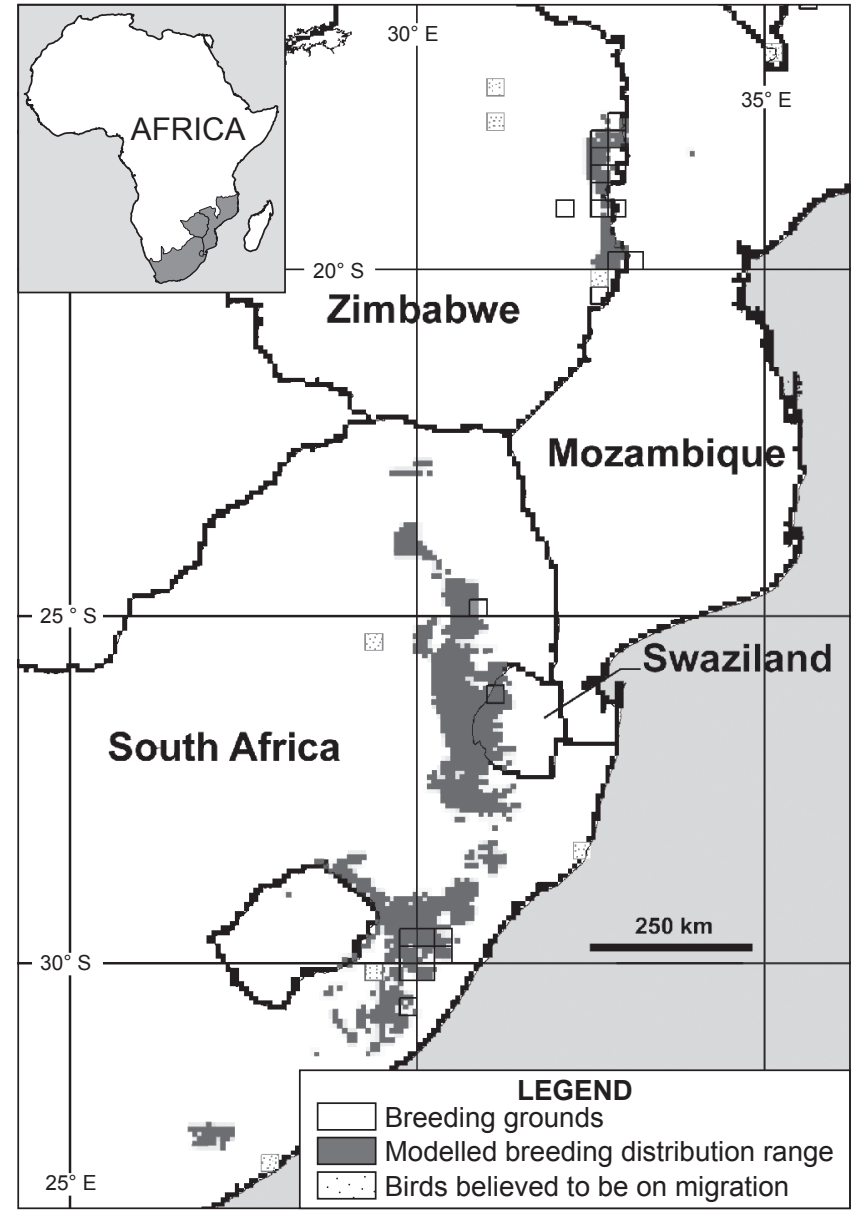

Figure 4: Modelled and current breeding distribution range of the Blue Swallow in the south of its range

single Blue Swallow near Korogwe dated April (Figure 3) (Brown and Britton 1980), there are no other records of Blue Swallows in these areas (Figure 3).

The modelled breeding distribution range failed to predict Blue Swallow habitat in the Marungu Highlands or Upemba National Park, both IBAs, in south-eastern DRC (Figure 3, Supplementary Table S3). Blue Swallows have, in the past two years, been observed in Upemba National Park (M Louette pers. comm., 2012).

\section{Population viability and minimum viable population size Sensitivity and conservativeness}

Of the four variables tested, the stochastic intrinsic rate of natural population change, measured as the stochastic number of individuals produced per season per Blue Swallow (stochastic $r$ ), and the probability of extinction $(\mathrm{PE})$ of the Blue Swallow were most sensitive to changes to first-year mortality rate, followed by changes to maximum adult breeding age, then to changes to adult mortality and lastly a decline in carrying capacity of areas occupied by unprotected metapopulations (Supplementary Figure S3). Vortex calculates PE as the number of iterations in which each metapopulation or the entire Blue Swallow population goes extinct as a fraction of the total number of iterations (Lacy et al. 2005; Miller and Lacy 2005).

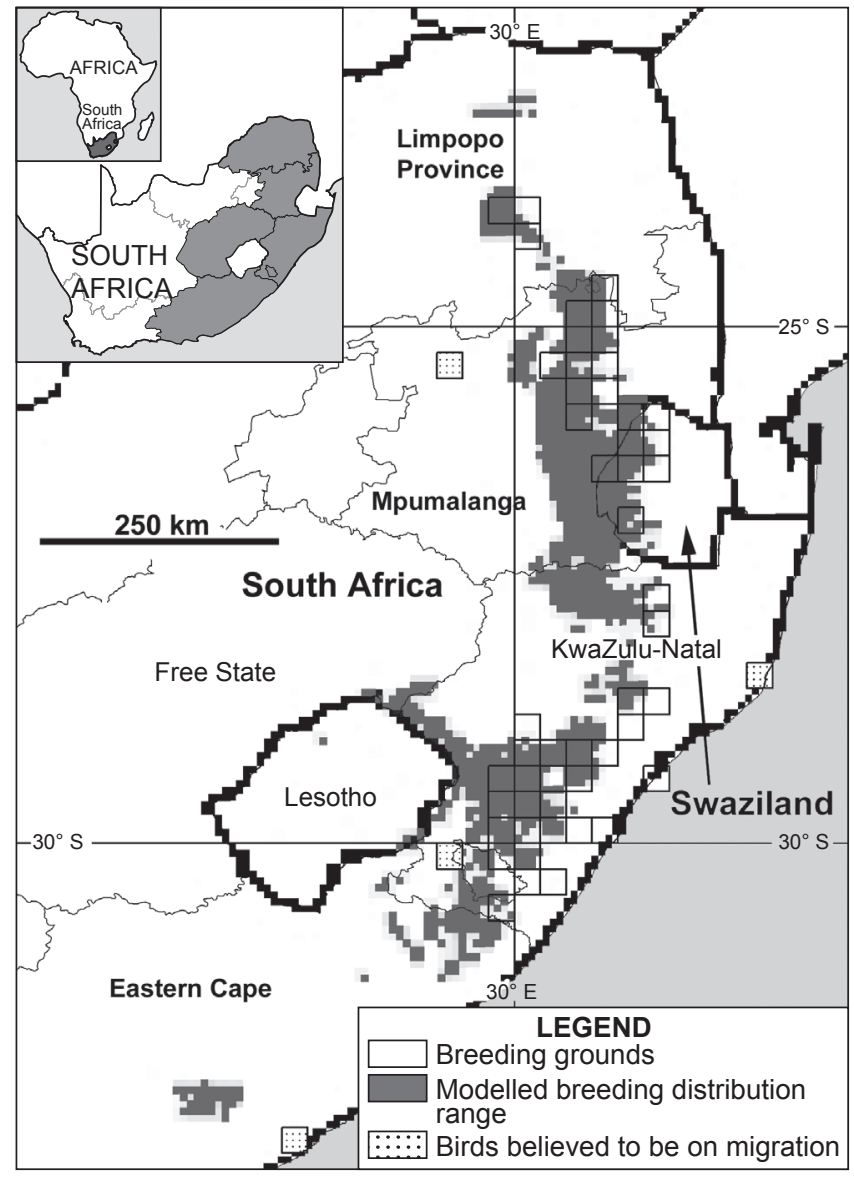

Figure 5: Modelled and historic breeding distribution range of the Blue Swallow in South Africa and Swaziland

Only one of the seven scenarios predicted a population decline (negative stochastic $r$ ) and also had the highest PE (Supplementary Figure S3). The Blue Swallow population was predicted to decline by $-0.032(S D=0.32)$ stochastic $r$ when first-year mortality rate was increased to $70 \%$ (from $65 \%$ in the baseline model) and predicted to have a PE of $75 \%$ (the baseline model predicted 3\%) (Supplementary Figure S3).

For the remaining six scenarios the Blue Swallow population was predicted to be increasing at different rates (positive stochastic $r$ ) (Supplementary Figure S3). Of these six scenarios, four predicted some PE (Supplementary Figure S3). The greatest PE was predicted when the maximum breeding age was reduced to three years or adult mortality was increased to $45 \%$, the Blue Swallow population was predicted to have a PE of $36 \%$ or $23 \%$, respectively, with stochastic $r$ of $0.012(S D=0.285)$ and 0.029 $(S D=0.28)$, respectively, compared with the baseline models prediction of a $3 \% \mathrm{PE}$ and a stochastic $r$ of 0.077 (0.24) (Supplementary Figures S2 and S3). By comparison, low PE of $2.7 \%$ and $0.3 \%$ was predicted due to a moderate decline in carrying capacity or an increase in adult longevity to five years, respectively (Supplementary Figure S3).

The remaining two scenarios predicted zero PE (Supplementary Figure S3). These two scenarios predicted rates of Blue Swallow population increase of 0.119 
$(S D=0.212)$ and $0.162(S D=0.202)$ when adult mortality was decreased to $35 \%$ or first-year mortality was reduced to $60 \%$, respectively (Supplementary Figure S3).

Based on changes to the PE and stochastic $r$ the values used in the baseline model to describe maximum breeding age (four years), annual adult mortality $(40 \%)$ and especially first-year mortality $(65 \%)$, appear to be near their upper limits. The baseline model was therefore considered to represent a conservative scenario for assessing the viability of the Blue Swallow population throughout its entire breeding range.

\section{Predicted rate of decline of the population}

Stochastic $r$ alone does not provide a measure of whether a population will ultimately remain stable, increase or decrease. This is because it is not a measure of absolute population size but only of the rate of change of a population at the points in time when it was determined (Pianka 2000). According to the baseline model the size of the Blue Swallow population decreased by a mean of $79.8 \%$, for all 20 metapopulations, from 2528 to 514 individuals from 2005 to 2105 and with a 3\% PE (Supplementary Figures S1 and S2). According to the scenario that includes a decline in carrying capacity, for areas occupied by unprotected breeding Blue Swallow metapopulations, the Blue Swallow population decreased by a mean of $80.1 \%$, for all 20 metapopulations, from 2528 to 437 individuals from 2005 to 2105 and with a $4 \% \mathrm{PE}$.

Blue Swallows that are considered to start and stop breeding at one and four years of age, respectively, have a calculated generation length (Pianka 2000) of 2.5 years. According to these figures, the Blue Swallow population would decline by $5.9-6 \%$ in three generations ( 7.5 years) or by $7.9-8 \%$ in 10 years.

\section{Predicted rates of decline of the meta-populations}

A reduction in habitat quality or quantity (modelled as a reduction in carrying capacity) was not included in the assessment of the Blue Swallow's viability. Except for their initial population size (Supplementary Table S2) all other variables were the same for each of the 20 Blue Swallow metapopulations. This resulted in all 20 metapopulations predicted as increasing by 0.11 deterministic calculation of the number of individuals produced per season per Blue Swallow or deterministic intrinsic rate of natural population change (deterministic $r$ ). In contrast to this is the much lower mean stochastic $r$ across all metapopulations of $0.063(S D=0.44$, minimum $=0.013$, maximum $=0.18)$. The probability of each of the 20 Blue Swallow metapopulations going extinct ranged from as high as $97 \%$ to as low as $16 \%$ (Supplementary Figure S3) with a mean across all metapopulations of $62 \%(S D=24)$.

The three Blue Swallow metapopulations, in the highlands in south-western Tanzania (SWTH), Nyanga Mountains (NM), and Nyika National Park (NNP), with the largest initial populations of 536, 400 and 520 individuals, respectively, were predicted to have a probability of going extinct of $27 \%, 50 \%$ and $25 \%$, respectively (Supplementary Figure S3). These three metapopulations were amongst the six metapopulations least likely $(<50 \%)$ to go extinct in the 100 years from 2005 to 2105 (Supplementary Figure S3).
Of all 20 metapopulations, the Blue Swallows of the South Umalila Mountains and Misuku Hills Forest Reserve (UMMFR), in Tanzania-Malawi, had the lowest predicted PE of $16 \%$, despite a moderate initial population size of only 80 individuals (Supplementary Figure S4, Table S2).

Two Blue Swallow metapopulations, the Blue Swallow Natural Heritage Site (BSNHS) in South Africa, and Mahamba Mountains (MAM) in Swaziland, have already gone extinct locally and are within the six Blue Swallow metapopulations predicted to have the highest probability $(>80 \%)$ of going extinct locally (Supplementary Figure S4). Not far behind is the Blue Swallow metapopulation of the Blyde River Canyon, Graskop Grasslands and Misty Mountain Natural Heritage Site (GG), which is currently down to eight birds and a predicted probability of extinction locally of $70 \%$ (Supplementary Figure S4, Table S2).

The only accurate estimate of a decline is for the Blue Swallow metapopulations in South Africa and Swaziland from 106 pairs in 2005 to 57 pairs in 2012, a decline of $54 \%$ over the past seven years (Supplementary Table S2). If this deterministic rate of decline is maintained, Blue Swallows in South Africa and Swaziland could be extinct locally within the next 13 years (by 2018) (Supplementary Table S2). According to these figures the South African and Swaziland Blue Swallow subpopulation have declined by $58 \%$ over the past three generations ( 7.5 years) or by $77 \%$ over the past 10 years.

\section{Minimum viable population size based on the eight metapopulation baseline models}

Similar to the baseline model, the predictions of the eight metapopulation baseline models (population predicted to have a $0.1-2 \% \mathrm{PE}$ ) to assess the minimum viable population size were most sensitive to a change in the first-year mortality rate, followed by changes to the maximum breeding age, and least sensitive to changes to adult mortality (Supplementary Figures $\mathrm{S} 1$ and $\mathrm{S} 2$ ). The minimum viable population size was a function of the number of individuals per metapopulation, which decreased non-linearly with an increase in the number of metapopulations (Supplementary Figures S1 and S2). Modelling the Blue Swallows as occurring in a single interbreeding population, with no metapopulations, indicated that even at a population size of 30000 individuals (the maximum that Vortex can model) there was a $>5 \%$ PE. Modelling the Blue Swallows as occurring in more than six metapopulations resulted in a small reduction in the number of individuals per metapopulation with each metapopulation added and the PE maintained at between $0.2 \%$ and $2 \%$ (Supplementary Figures S1 and S2). Aiming to maintain a range of four to six Blue Swallow metapopulations could be an initial conservation target. Four to six metapopulations should contain a minimum of 900 to 500 individuals per metapopulation, respectively, or total populations of 3600 to 3000 individuals (Supplementary Figures S1 and S2). Only the south-western Highlands of Tanzania and Nyika National Park (NNP), the two largest Blue Swallow metapopulations, are currently considered to contain the minimum proposed Blue Swallow metapopulation of 500 individuals each. The only other population approaching the proposed minimum 
of 500 individuals is Nyanga Mountains (NM), in Zimbabwe, with 400 individuals (Supplementary Table S2).

Four to six Blue Swallow metapopulations of 3600 and 3000 individuals, respectively, means that the current estimated Blue Swallow population of 2434 individuals is $32 \%$ to $19 \%$ below the two proposed conservation targets for the Blue Swallow population.

An important consideration was that dispersing individuals were modelled as resulting in the exchange of individuals between adjacent metapopulations (Supplementary Figures S1 and S3). In addition to the size of each metapopulation, the number of metapopulations should be selected so that their geographic distribution maximises the probability that birds disperse to and from at least one, but preferably two or more, neighbouring metapopulations. As a migrant the Blue Swallow may be able to disperse over longer distances compared with what resident species might be capable of.

\section{Application of the minimum viable population size derived from the models to the Blue Swallow distribution}

The 17 current Blue Swallow breeding metapopulations are distributed between four more or less distinct geographic areas or clusters of Blue Swallow metapopulations (Table 1, Supplementary Figures S1 and S2). These four clusters consist of (1) two metapopulations in south-eastern DRC (Figure 1a), (2) six metapopulations in the southern highlands of Tanzania and northern Malawi (Figure 1a), (3) five metapopulations in the eastern highlands of Zimbabwe (Figure 1b) and (4) three extant and two locally extinct metapopulations in South Africa and Swaziland (Figure 1c). The one definite (Mount Mulanje [MM]) and one possible metapopulation (KR) in southern Malawi are located midway between the cluster of Blue Swallow metapopulations in northern Malawi and those in eastern Zimbabwe (Figure 1a). Blue Swallows may recolonise the BSNHS as suitable habitat still exists (Figure 1c). In order to attain a Blue Swallow population of 3600 individuals, conservation measures should be implemented to increase the number of Blue Swallows in each of these four clusters to a minimum of 900 individuals. In addition, at least one of the metapopulations in each cluster should contain a minimum of 500 individuals. Currently, only the cluster of six metapopulations in the southern highlands of Tanzania and northern Malawi meet these minimum requirements with a total subpopulation of 1436 individuals of which 536 individuals are in one metapopulation in the south-western section of the highlands in south-western Tanzania (Figure 1a, Table 1, Supplementary Tables S2-S4).

In conjunction with maintaining viable breeding metapopulations is the need to maintain Blue Swallow subpopulations on their non-breeding range in north-western Tanzania, north-eastern DRC, southern Uganda and western Kenya (Evans and Bouwman 2010a). Currently, north-western Tanzania, north-eastern DRC, southern Uganda and western Kenya contain approximately $10 \%$, $5 \%, 60 \%$ and $25 \%$, respectively, of the Blue Swallow non-breeding population. Based on these proportions, in order to achieve a population target of 3600 Blue Swallows, the north-western Tanzanian, north-eastern DRC, southern
Ugandan and western Kenyan non-breeding subpopulations should each be increased to a minimum of 360, 180, 2160 and 900 individuals, respectively (Table 1).

\section{Current conservation status}

The Blue Swallow qualifies for red-listing as Vulnerable according to the IUCN/SSC (2012) criteria C2a(i) for the following reasons. First, the Blue Swallow population, estimated at less than 1500 individuals, falls below the threshold of 10000 mature individuals. Second, there is a continuing observed decline in the numbers of mature individuals. Third, no Blue Swallow metapopulation was considered to consist of more than 1000 mature individuals.

Per country, the Blue Swallows in South Africa, Swaziland, Mozambique, Zambia and Kenya are red-listed as Critically Endangered. In the DRC and Uganda, they are Endangered, and in Tanzania, Malawi and Zimbabwe they are Vulnerable. Supplementary Table S5 summarises the IUCN (2012) criteria according to which the Blue Swallows in each country qualified as either Critically Endangered, Endangered or Vulnerable.

A small portion of the Nyika Plateau extends into Zambia from Malawi, and is strictly protected in both countries (Stjernstedt 2004). Due to this naturally limited habitat, the number of Blue Swallows on the Zambian side of the Nyika Plateau has probably never been much higher than it currently is. As the Zambian subpopulation is continuous with the birds in Malawi, on the Nyika Plateau, the conservation status of the birds in both countries should be assessed together. Together the Blue Swallows in Zambia and Malawi would be classified as Vulnerable according to the IUCN/SSC (2012) criteria.

\section{Discussion}

\section{Conservation, habitat availability, surveys, protection} and IBA network

Although models are useful, it is important to keep in mind that a limitation of habitat suitability models is that they are seldom entirely accurate in their predictions (Phillips et al. 2006; Hebblewhite et al. 2011). However, supported by field verification, models are a useful cost- and time-effective initial means of screening for suitable habitat for a species. Our species distribution model of the breeding range of Blue Swallows predicted that they would occur in several sites where they have not previously been recorded: two sites in southern and south-western Malawi and southwestern Tanzania (Figure 3). Although Blue Swallows have not been previously recorded in these areas (DowsettLemaire and Dowsett 2006; Baker and Baker 2012) it is recommended that these three areas be surveyed for Blue Swallows. Both Tanzania and Malawi have very few active bird-watchers and all three sites are in unprotected areas that would not facilitate being visited by bird-watchers. For these reasons Blue Swallows in these three areas may have been overlooked.

In South Africa, the primary reason the predicted breeding range is more extensive compared with the birds current breeding range (Figures 4 and 5 ) is because areas that no longer contain suitable habitat for Blue Swallows, 
Table 1: Current estimated Blue Swallow numbers and proportions that are protected throughout their breeding and non-breeding ranges

\begin{tabular}{|c|c|c|c|c|c|c|c|c|c|c|c|c|}
\hline \multirow[b]{2}{*}{$\begin{array}{l}\text { Clusters of meta- } \\
\text { (breeding range) } \\
\text { and sub-populations } \\
\text { (non-breeding range) }\end{array}$} & \multirow[b]{2}{*}{$\begin{array}{l}\text { No. of extant } \\
\text { meta- } \\
\text { populations }\end{array}$} & \multirow{2}{*}{$\begin{array}{c}\text { Formally } \\
\text { protected } \\
\text { No. of locally } \\
\text { extinct meta- } \\
\text { populations }\end{array}$} & \multirow{2}{*}{$\begin{array}{c}\text { Partially } \\
\text { protected and } \\
\text { unprotected } \\
\text { No. of } \\
\text { possible } \\
\text { meta- } \\
\text { populations }\end{array}$} & \multicolumn{6}{|c|}{$\begin{array}{l}\text { Current proportion of individuals that are } \\
\text { strictly protected and unprotected }\end{array}$} & \multicolumn{3}{|c|}{ Conservation targets } \\
\hline & & & & $\begin{array}{l}\text { Current } \\
\text { total no. of } \\
\text { individuals }\end{array}$ & $\begin{array}{l}\text { Current no. } \\
\text { of individuals } \\
\text { in the largest } \\
\text { meta- } \\
\text { population }\end{array}$ & $\begin{array}{l}\text { Current no. } \\
\text { of individuals } \\
\text { in strictly } \\
\text { protected } \\
\text { areas }\end{array}$ & $\begin{array}{l}\% \text { of } \\
\text { total }\end{array}$ & $\begin{array}{l}\text { Current no. } \\
\text { of individuals } \\
\text { in partially } \\
\text { protected and } \\
\text { unprotected } \\
\text { areas }\end{array}$ & $\begin{array}{l}\% \text { of } \\
\text { total }\end{array}$ & $\begin{array}{l}\text { Minimum } \\
\text { total } \\
\text { conservation } \\
\text { target per } \\
\text { cluster }\end{array}$ & $\begin{array}{l}\text { Percentage } \\
\text { above or } \\
\text { below the } \\
\text { minimum } \\
\text { conservation } \\
\text { target per } \\
\text { cluster }\end{array}$ & $\begin{array}{c}\text { Percentage } \\
\text { above or below } \\
\text { the target of a } \\
\text { minimum of } 500 \\
\text { individuals for one } \\
\text { meta-population } \\
\text { per cluster }\end{array}$ \\
\hline \multicolumn{13}{|l|}{ Breeding range } \\
\hline South-eastern DRC & 2 & & & 200 & 100 & 100 & 50 & 100 & 50 & 900 & -78 & -80 \\
\hline $\begin{array}{l}\text { Southern highlands of } \\
\text { Tanzania and northern } \\
\text { Malawi }\end{array}$ & 6 & & & 1436 & 776 & 600 & 42 & 836 & 58 & 900 & 60 & 55 \\
\hline $\begin{array}{l}\text { Eastern highlands of } \\
\text { Zimbabwe }\end{array}$ & 5 & & & 620 & 400 & 400 & 65 & 220 & 35 & 900 & -31 & -20 \\
\hline $\begin{array}{l}\text { South Africa and } \\
\text { Swaziland }\end{array}$ & 3 & 2 & & 98 & 70 & 44 & 45 & 54 & 55 & 900 & -89 & -86 \\
\hline Southern Malawi & 1 & & 1 & 80 & 60 & 20 & 25 & 60 & 75 & & & \\
\hline Total & 17 & 2 & 1 & 2434 & & 1164 & 48 & 1270 & 52 & 3600 & -32 & \\
\hline \multicolumn{13}{|l|}{ Non-breeding range } \\
\hline North-western Tanzania & 1 & & & 243 & & & & 243 & 100 & 360 & -33 & \\
\hline North-eastern DRC & 1 & & & 122 & & & & 122 & 100 & 180 & -32 & \\
\hline Southern Uganda & 3 & 2 & & 1460 & & & & 1460 & 100 & 2160 & -32 & \\
\hline $\begin{array}{l}\text { South-western Kenya and } \\
\text { north-eastern Tanzania }\end{array}$ & 2 & 1 & & 609 & & 609 & 100 & & & 900 & -32 & \\
\hline Total & 7 & 3 & & 2434 & & 609 & 25 & 1825 & 75 & 3600 & -32 & \\
\hline
\end{tabular}


i.e. transformed areas, were not removed from the birds modelled breeding distribution range. The modelled breeding distribution range represents the possible distribution of Blue Swallows prior to extensive human-induced changes to the landscape, such as urban development, commercial forestry and crop agriculture.

In addition to the species distribution model, the current knowledge distribution maps we produced suggest other areas where surveys should ideally be conducted. On their breeding range, and within existing IBAs, surveys of Blue Swallows in the Marungu Highlands IBA and Upemba National Park, in the DRC, are recommended as, despite the presence of Blue Swallows being confirmed in both areas (Figure 1a), no survey has ever been done. For the same reason a survey of Blue Swallows on the Lendu Plateau IBA, part of their non-breeding range, in northeastern DRC is recommended (Figure 2). Evans and Bouwman (2010a) suggested that the Blue Swallows in the DRC may be a separate population, west of the Albertine Rift, from the rest of the Blue Swallows all located to the east of the Albertine Rift (Figures 1a and 2).

On their breeding range, and within unprotected areas, a survey of Blue Swallows in the Kirk Range (Mount Tsangano), on the border between Malawi and Mozambique (Figure 1a), is recommended. Despite the presence of Blue Swallows having been documented in this area in the 1940s (Benson 1942), no survey has ever been done. In the event that Blue Swallows are found on Mount Tsangano and its surroundings, the area should be considered for selection as an IBA.

Due to the popularity of the Masai Mara and Serengeti National Parks and the number of bird-watchers that visit them, it seems unlikely that non-breeding Blue Swallows would previously have been overlooked. Consequently, these past and current records of Blue Swallows in the Masai Mara-Serengeti National Parks suggest that Blue Swallows have extended their non-breeding range into this area. On their non-breeding range, and within existing IBAs, surveys of Blue Swallows in the Masai Mara and Serengeti National Parks are recommended as this may be a recent addition to the birds' non-breeding range (Figure 2). In addition, surveys of Blue Swallows are recommended for the area south of Asembo along the shores of Lake Victoria as this may be a previously unknown part of the birds' non-breeding range (Figure 2). This survey should include Blue Swallows and all other bird species that may qualify this unprotected area as an IBA. Approximately $55 \mathrm{~km}$ to the south-west of Asembo is Ruma National Park IBA, home to non-breeding Blue Swallows (Ndang'ang'a 2007; Ogoma 2013) (Figure 2). Approximately $74 \mathrm{~km}$ to the northwest of Asembo is the Busia Grasslands IBA, at which Blue Swallows have gone locally extinct (P Njoroge pers. comm., 2013) (Supplementary Table S2).

The local extinction of Blue Swallows adjacent to Mabira Forest, in Uganda (Figure 2), was probably due to urban and crop agricultural expansion and the expansion of commercial sugarcane plantations nearby (SWE pers obs.). The Blue Swallow observed adjacent to the Virunga National Park, in the DRC (Figure 2), was probably an example of vagrancy, as only a single bird was observed and this was approximately $800 \mathrm{~km}$ north of the birds nearest known breeding area, the Marungu Highlands IBA (Figure 2).

All areas recommended for surveys for Blue Swallows, and currently not listed as IBAs, should be considered for selection as IBAs if their presence there is confirmed. Although it would be ideal to obtain strict protection for all sites containing Blue Swallows, this is unrealistic as many of these unprotected sites are home to a large number of people depending on the resources of these areas for their survival. Listing all sites that are known to contain Blue Swallows as IBAs is a relatively easy process. As these sites already contain a threatened species, the Blue Swallow, they tentatively qualify as an IBA by meeting one of the four criteria used to select IBAs. The IBA criteria are a useful tool for advocating for the conservation of threatened species and biodiversity within these areas. Countries that have a protected areas expansion plan might consider IBAs for strict protection prior to any unprotected site that is not recognised as an IBA.

\section{Population viability and minimum viable population size} Vortex is a stochastic model for assessing population viability and as such cannot be a perfect description of reality (McCarthy et al. 2001). Despite the uncertainty in the Vortex model constructed for the Blue Swallow, it remains a useful tool for completing an initial assessment of the viability of the Blue Swallow population, its metapopulations and in estimating a MVP for the Blue Swallow. The uncertainty arises because first-year mortality, breeding longevity and annual adult mortality for the Blue Swallow are not known (Supplementary Figures S1-S4). In addition, the declines in the carrying capacity of each of the unprotected areas occupied by Blue Swallows are not known (Supplementary Figures S1-S4). Declines in carrying capacity were estimated from mean rates of decline at the QDGC level and could result in an underestimation of the rate of decline in carrying capacity as only changes at a large scale $\left(>700 \mathrm{~km}^{2}\right)$ would be detected and changes at a smaller scale $\left(<700 \mathrm{~km}^{2}\right)$ would remain undetected (Figures 1a-c, 2-4).

In order to improve the Vortex model and its usefulness in assessing the viability of the Blue Swallow population, it is recommended that first-year mortality, breeding longevity and annual adult mortality be determined at a minimum of one of the metapopulations in each of the four Blue Swallow metapopulation clusters identified (Figures 1a-c, 2-4). In addition, the decline in carrying capacity (both habitat quantity and quality) should be determined for all remaining Blue Swallow metapopulations and conservation education, awareness, advocacy and research initiated to stop and ultimately reverse this trend. An advantage to developing the model is that it has drawn attention to these key variables still unknown for the Blue Swallow and therefore highlighted these as priorities for research.

Including any change in carrying capacity is made difficult because only the metapopulations on the birds breeding range, and not on their non-breeding range, is modelled. These are interlinked, as a decline on the birds non-breeding range would result in a decline in the Blue Swallow population on the breeding range. The concentration of individuals and greater proportion of birds 
occupying unprotected areas on their non-breeding range suggests that these areas may be being lost at a greater rate than on the breeding range where a larger proportion of the population is in strictly protected areas (Table 1, Supplementary Table S2). In areas such as the BSNHS and GG, the number of birds is declining but the available habitat has remained constant. This suggests that the decline in the Blue Swallow metapopulation size in these areas is not due to current habitat loss but to a combination of stochastic effects on small populations, as well as the loss of habitat in other parts of the birds migratory and non-breeding range.

Due to the uncertainties (Supplementary Figures S2 and S3) in the model and MVP assessment, the conservation targets recommended for the Blue Swallow should be considered to be minimum targets and should be achieved and preferably exceeded in order to conserve the Blue Swallow. The advantage of having targets is that they provide goals towards which conservationists can work and, if achieved, provide a natural experiment for retrospectively evaluating the usefulness and accuracy of the model and its predictions. This research would improve the use of similar models in assessing other threatened species' risk of extinction and its application in completing MVP assesments and setting conservation targets of the population sizes for other threatened species.

\section{Viability of small metapopulations located near to large metapopulations}

UMMFR is located between SWTH and NNP, and would be recolonised after a local extinction event by birds dispersing from SWTH and NNP, two of the three largest initial Blue Swallow metapopulations of 360 and 520 individuals, respectively (Table 1 ). Similarly, birds dispersing from two of the three largest Blue Swallow metapopulations from NNP to North Viphya (NV) to its north and from SWTH to the north-eastern part of the highlands in south-western Tanzania (NETH) to the north-east resulted in the recovery of these two smaller populations after local extinction events (Figure 1a). This indicates that the viability of small Blue Swallow metapopulations can be improved by being near to large metapopulations from which individuals can disperse to the smaller populations and recolonise them in the event of a local extinction. The dispersal of individuals between neighbouring metapopulations and recolonisation of metapopulations after going extinct results in the low prediction of $3 \%$ for the PE of the species compared with the much higher PE predicted independently for each metapopulation, which ranged from $16 \%$ to $97 \%$. In other words, the probability that all Blue Swallow metapopulations go extinct simultaneously is $3 \%$.

\section{Current extent of protection and conservation status}

In the present study, mean Blue Swallow longevity was conservatively estimated at four years and three generation lengths calculated according to the method described by Pianka (2000) as 7.5 years. This resulted in an estimate of a decline by $5.9-6 \%$ in three generations (7.5 years) or $7.9-8 \%$ in 10 years. This estimate is lower than the decline of $12 \%$ over three generations (18 years) estimated by Evans and Bouwman (2010a) and is due to longevity being estimated at six years and three generations equating to 18 years. The method for determining generation length described by Pianka (2000) is more accurate and widely accepted and therefore used in the present study.

On their non-breeding grounds the current proportion of Blue Swallows in strictly protected and unprotected areas of $25 \%$ and $75 \%$, respectively (Table 1 ), is similar to the $28 \%$ and $72 \%$ in 2005 reported by Evans and Bouwman (2010a). No new formally protected areas have been proclaimed throughout the birds' non-breeding range over the seven years separating the respective studies. Because of the revision of the number of individuals in the south-western highlands of Tanzania from 320 to 776 individuals, all in unprotected areas, the current proportion of Blue Swallows in strictly protected and unprotected areas of $48 \%$ and $52 \%$, respectively (Table 1), is different to the $60 \%$ and $40 \%$ in 2005 reported by Evans and Bouwman (2010a).

\section{Conclusions and recommendations}

Based on our species distribution model and updated current distribution maps for Blue Swallows, we recommend that surveys be conducted in a number of strictly protected and unprotected sites that may contain breeding and non-breeding subpopulations of Blue Swallows. During these surveys the minimum data that should be collected are the coordinates and the number of male, female and immature Blue Swallows observed (point data). The primary purpose of these surveys should be to determine the distribution and size of the Blue Swallow population in the area surveyed. The point data for both the breeding and especially the non-breeding range can be used to update the Blue Swallows modelled breeding distribution range, and develop a model predicting their non-breeding range. Once models such as these have been developed, they could be used to predict the magnitude and extent of the threat that climate change poses to the Blue Swallow and its habitat, as was done for the Sokoke Scops Owl Otus ireneae (Monadjem et al. 2013).

The size of the Blue Swallow population, as well as the quantity and quality of its grassland and wetland habitat on both its breeding and non-breeding range, continues to decline. Conservation education, awareness, advocacy and research initiated to stop and ultimately reverse these trends needs to be intensified.

MVP analysis indicates that a goal for the long-term conservation of the Blue Swallow should be to mitigate current threats that are driving declines, such that the population increases to a minimum of 3600 individuals. This should consist of a minimum of 900 individuals in each of the four clusters identified, along with a minimum of 500 individuals in at least one of the metapopulations per cluster.

Blue Swallows areas, especially on the birds' non-breeding range need to be selected and managed as strictly protected areas. First-year mortality, breeding longevity and annual adult survival/mortality of Blue Swallows must be determined at a minimum of one of the metapopulations in each of the four clusters of Blue Swallow metapopulation identified. 
In addition, the decline in carrying capacity (both habitat quantity and quality) should be determined for all remaining Blue Swallow metapopulations.

All areas recommended for surveys for Blue Swallows and not listed as IBAs should be considered for selection as IBAs if the presence of Blue Swallows in them is confirmed.

The viability of small metapopulations can be improved by being near to large metapopulations from which individuals can disperse to the smaller populations and recolonise in the event of a local extinction.

According to our current analysis of the IUCN/SSC (2012) criteria, the Blue Swallow's red-listing status should remain Vulnerable (BirdLife International 2000; Evans and Bouwman 2010a; BirdLife International 2012).

Acknowledgements - Paul Matiku, Achilles Byaruhanga, Warwick Tarboton, David Johnson, Peter Mundy, Bob Dowsett and Francois Dowsett-Lemaire are thanked for their contributions to this research.

\section{References}

Baker EM, Baker NE. 2009. A survey of the Blue Swallow Hirundo atrocaerulea in the Southern Highlands of Tanzania during the 2008/09 breeding season. Unpublished report.

Baker NE, Baker EM. 2012. The birds of Tanzania: an atlas of distribution and seasonality. Available at http://www. tanzaniabirdatlas/ [accessed March 2012].

Beaumont LJ, Gallagher RV, Leishman MR, Hughes L, Downey PO. 2005. How can knowledge of the climate niche inform the weed risk assessment process? A case study of Chrysanthemoides monilifera in Australia. Diversity and Distributions 20: 613-625.

Beklova M. 1976. Contribution to the characteristics of population dynamics of certain hemisyananthropic species of bird. Zoo List 25: 147-155.

Bennun L, Njoroge P (eds). 1996. Birds to watch in East Africa: a preliminary red data list. Research Reports of the Centre for Biodiversity, National Museums of Kenya: Ornithology no. 23. Nairobi: National Museums of Kenya.

Benson CW. 1942. Additional notes on Nyasaland birds. Ibis 6: 299-337.

BirdLife International. 2000. Threatened birds of the world. Barcelona: Lynx Edicions; Cambridge: BirdLife International.

BirdLife International. 2012. Hirundo atrocaerulea. In: IUCN Red List of Threatened Species. Version 2012.2. Available at http:// www.iucnredlist.org [accessed 1 April 2013].

BirdLife International and Durham University. 2013. Species climate change impacts factsheet: Hirundo atrocaerulea. Available at http://www.birdlife.org [accessed 26 June 2013].

BirdLife Zimbabwe. 2004. Zimbabwe National Blue Swallow Action Plan. Blue Swallow Conservation Action Plan Workshop. Harare: BirdLife Zimbabwe.

Boyce MS. 1992. Population viability analysis. Annual Review of Ecology and Systematics 23: 481-506.

Brown LH, Britton PL. 1980. The breeding seasons of East African birds. Nairobi: East African Natural History Society.

Bryant DM. 1975. Breeding biology of house martins Delicon urbica in relation to aerial insect abundance. Ibis 117: 180-216.

Cassini MH. 2011. Ecological principles of species distribution models: the habitat matching rule. Journal of Biogeography 38 : 2057-2065.

Childes SL. 2001. Blue Swallow (Hirundo atrocaerulea) status and distribution in Zimbabwe. Unpublished report. Harare: BirdLife Zimbabwe.
CMS (Convention on the Conservation of Migratory Species of Wild Animals). 2003. Convention text: Convention on the Conservation of Migratory Species of Wild Animals. Available at http://www.cms.int [accessed 15 April 2013].

Combrink L, Little IT (eds). 2012. Review of the Blue Swallow International Action Plan and regional red list assessments: summary of an international workshop 2012. Johannesburg: Endangered Wildlife Trust.

Cramp S (ed.) 1988. The birds of the western Palearctic, vol. 5. Oxford: Oxford University Press.

DeMeyer M, Robertson MP, Peterson AT, Mansell MW. 2008. Ecological niches and potential geographic distributions of Mediterranean fruit fly (Ceratitis capitata) and Natal fruit fly (Ceratitis rosa). Journal of Biogeography 35: 270-281.

Dowsett-Lemaire F. 2006. Notes supplementary to The Birds of Malawi (2006). Tauraco Research Report 8: 65-121.

Dowsett-Lemaire F, Dowsett RJ. 2006. The birds of Malawi. Liège: Tauraco Press.

Dowsett-Lemaire F, Dowsett RJ, Dyer M. 2001. Malawi. In: Fishpool LDC, Evans MI (eds), Important Bird Areas of Africa and associated islands: priority sites for conservation. Bird Conservation Series no. 11. Newbury: Pisces Publications; Cambridge: BirdLife International. pp 539-555.

Elith J, Leathwick JR. 2009. Species distribution models: ecological explanation and prediction across space and time. Annual Review of Ecology, Evolution and Systematics 40: 677-697.

Elith J, Phillips SJ, Hastie T, Dudík M, Chee YE, Yates CJ. 2011. A statistical explanation of MaxEnt for ecologists. Diversity and Distribution 17: 43-57.

Evans SW. 2008. The conservation ecology and breeding biology of the Blue Swallow Hirundo atrocaerulea, Sundevall 1850, in South Africa. PhD thesis, North-West University, South Africa.

Evans SW. In press. Blue Swallow Hirundo atrocaerulea. In: Taylor ML (ed.), Eskom red data book of birds of South Africa, Lesotho and Swaziland. Johannesburg: BirdLife South Africa.

Evans SW, Baker EM, Baker NE, Cilliers D. In press. Current distribution and population size of the Blue Swallow Hirundo atrocaerulea in the southern highland grasslands of Tanzania. Ostrich

Evans SW, Barnes KN. 2000. Blue Swallow Hirundo atrocaerulea. In: Barnes KN (ed.), The Eskom red data book of birds of South Africa, Lesotho and Swaziland. Johannesburg: BirdLife South Africa. pp 32-34.

Evans SW, Biggs D, van Zyl C, Cohen L, McNamara M, McCartney S, Krynaw S, Burden D, Mattison H, Friedmann Y (eds). 2003. Blue Swallow (Hirundo atrocaerulea) population and habitat viability assessment (PHVA). Draft Workshop Report. [s.I.]: Conservation Breeding Specialist Group (IUCN/SSC) Southern Africa; Johannesburg: Endangered Wildlife Trust.

Evans SW, Bouwman H. 2010a. Historical and current distribution, population size, and possible migration routes of the Blue Swallow Hirundo atrocaerulea in Africa. Bird Conservation International 20: 240-254.

Evans SW, Bouwman H. 2010b. Habitat selection by blue swallows Hirundo atrocaerulea Sundevall, 1850 breeding in South Africa and its implications for conservation. African Journal of Ecology 8: 871-879.

Evans SW, Cohen L, Sande E, Monadjem A, Hoffmann D, Mattison H, Newbery P, Ndang'ang'a K, Friedmann Y (eds). 2002. Blue Swallow (Hirundo atrocaerulea) International Action Plan. Final Workshop Report. [s.I.]: Conservation Breeding Specialist Group South Africa; Johannesburg: Endangered Wildlife Trust.

Fishpool LDC, Evans MI (eds). 2001. Important Bird Areas in Africa and associated islands: priority sites for conservation. BirdLife Conservation Series no. 11. Newbury: Pisces Publications; Cambridge: BirdLife International.

Fitzpatrick MC, Gotelli NJ, Ellison AM. 2013. MaxEnt versus 
MaxLike: empirical comparisons with ant species distributions. Ecosphere 4(5): 55.

Gibson L, Barrett B, Burbidge A. 2007. Dealing with uncertain absences in habitat modelling: a case study of a rare grounddwelling parrot. Diversity and Distributions 13: 704-713.

Hebblewhite M, Miquelle DG, Murzin AA, Aramilev VV, Pikunov DG. 2011. Predicting potential habitat and population size for reintroduction of the far eastern Leopards in the Russian far east. Biological Conservation 144: 2403-2413.

Hernandez P, Franke I, Herzog S, Pacheco V, Paniagua L, Quintana H, Soto A, Swenson J, Tovar C, Valqui T, Vargas J, Young B. 2008. Predicting species distributions in poorly-studied landscapes. Biodiversity and Conservation 17: 1353-1366.

Hernandez PA, Graham CH, Master LL, Albert DL. 2006. The effect of sample size and species characteristics on performance of different species distribution modelling methods. Ecography 29: 773-785.

Hijmans HJ, Cameron SE, Parra JL, Jones PG, Jarvis A. 2005. Very high resolution interpolated climate surfaces for global land areas. International Journal of Climatology 25: 1965-1978.

IUCN/SSC (International Union for the Conservation of Nature and Natural Resources/Species Survival Commission). 2012. IUCN Red List categories and criteria, version 3.1, second edition. Gland: IUCN/SSC

Keith S, Urban EK, Fry CH (eds). 1992. Birds of Africa, vol. 4. London: Academic Press.

Kylin H, Bouwman H, Evans SW. 2011. Evaluating threats to an endangered species by proxy: air pollution as threat to the blue swallow (Hirundo atrocaerulea) in South Africa. Environmental Science and Pollution Research 18: 282-290.

Lacy RC, Borbat M, Pollak JP. 2005. VORTEX: a stochastic simulation of the extinction process. Version 9.50. Brookfield, IL: Chicago Zoological Society

Lamb JM, Ralph TMC, Goodman SM, Bogdanowicz W, Fahr J, Gajewska M, Bates PJJ, Eger J, Benda P, Taylor PJ. 2008. Phylogeography and predicted distribution of African-Arabian and Malagasy populations of giant mastiff bats, Otomops spp. (Chiroptera: Molossidae). Acta Chiropterologica 10: 21-40.

McCarthy MA, Possingham HP, Day JR, Tyre AJ. 2001. Testing the accuracy of population viability analysis. Conservation Biology 15: $1030-1038$

Mead C. 1979. Mortality and causes of death in British Sand Martins. Bird Study 26: 107-112.

Miller PS, Lacy RC. 2005. VORTEX: a stochastic simulation of the extinction process. Version 9.50 User's Manual. Apple Valley, MN: Conservation Breeding Specialist Group (SSC/IUCN).

Møller AP. 1984. Geographic trends in breeding parameters of Swallows, Hirundo rustica and House Martins Delichon urbica. Ornis Scandinavica 15: 43-54.

Møller AP. 1988. Female choice selects for male sexual tail ornaments in the monogamous swallow. Nature 332: 640-642.

Monadjem A, Boycott RC, Parker V, Culverwell J. 2003. Threatened vertebrates of Swaziland. Swaziland red data book: fish, amphibians, reptiles, birds and mammals. Mbabane: Ministry of Tourism, Environment and Communications.

Monadjem A, Virani MZ, Jackson C, Reside A. 2013. Rapid decline and shift in the future distribution predicted for the endangered Sokoke Scops Owl Otus ireneae due to climate change. Bird Conservation International 23: 247-258.

Mwizabi D, Nkandu B, Mwiya EK, Bingham M, Moonga W, Shawa
J, Kamweneshe B, Stjernstedt B, Evans, SW. 2003. Zambian Blue Swallow Hirundo atrocaerulea Action Plan. Lusaka: Zambian Ornithological Society and Zambian Wildlife Authority.

Ndang'ang'a K. 2007. Blue Swallow Hirundo atrocaerulea in Kenya: status survey and conservation options. Scopus 26: 1-9.

Ogoma M. 2013. Ecological survey and status of Blue Swallow Hirundo atrocaerulea in Ruma National Park, Kenya. Unpublished report to the African Bird Club.

Parker V. 1994. Swaziland bird atlas 1985-1991. Mbabane: Websters.

Peach WJ, Hanmer DB, Oatley T. 2001. Do southern African songbirds live longer than their European counterparts? Oikos 93: 235-249.

Pearson RG, Raxworthy CJ, Nakamura M, Peterson TA. 2007. Predicting species distributions from for small numbers of occurrence records: a test case using cryptic geckos in Madagascar. Journal of Biogeography 34: 102-117.

Perrins C. 1971. Age of first breeding and adult survival rates in the Swift. Bird Study 18: 61-70.

Phillips SJ, Dudík M. 2008. Modelling of species distributions with MaxEnt: new extensions and a comprehensive evaluation. Ecography 31: 161-175.

Phillips SJ, Dudík M, Schapire RE. 2004. A maximum entropy approach to species distribution modelling. In: Greiner R, Schuurmans D (eds), Proceedings of the 21st International Conference on Machine Learning, Banff, Canada, 4-8 July 2004. Menlo Park, CA: ACM Press. pp 655-662.

Pianka ER. 2000. Evolutionary biology (6th edn). San Francisco: Addison Wesley Educational Publishers.

Rydzewski W. 1978. The longevity of ringed birds. Ring 96-97: 218-262.

Simmons RE, Barnard P, Dean WRJ, Midgley GF, Thuiller W, Hughes G. 2005. Climate change and birds: perspectives and prospects from southern Africa. Ostrich 75: 295-308.

Stabach JA, Laporte N, Olupot W. 2009. Modelling habitat suitability for Grey Crowned-cranes (Balearica regulorum gibbericeps) throughout Uganda. International Journal of Biodiversity and Conservation 1: 177-186.

Stjernstedt R. 2004. Preliminary survey of Blue Swallows on Nyika Plateau in Zambia. Unpublished report.

Thuiller W, Richardson DM, Pysek P, Midgley GF, Hughes GO, Rouget M. 2005. Niche-based modelling as a tool for predicting the global risk of alien plant invasions. Global Change Biology 11: 2234-2250

Turner A, Rose C. 1989. A handbook to the Swallows and Martins of the world. London: Christopher Helm.

Wakelin J, Hill TR. 2007. The impact of land transformation on breeding Blue Swallows Hirundo atrocaerulea Sundevall, in KwaZulu-Natal, South Africa. Journal of Nature Conservation 15: 245-255.

Wakelin J, McKechnie E, Woodborne S. 2011. Stable isotope analysis of migratory connectivity in a threatened intra-African migrant, the Blue Swallow (Hirundo atrocaerulea). Journal of Ornithology 152: 171-177.

Wisz MS, Hijmans RJ, Peterson AT, Graham CH, Guisan A. 2008. Effects of sample size on the performance of species distribution models. Diversity and Distributions 14: 763-773.

Zimmerman DA, Turner DA, Pearson DJ. 1996. Birds of Kenya and northern Tanzania. Halfway House: Russell Friedman Books. 


\section{Supplementary Information}

Table S1: The categorical and continuous environmental variables used in Maxent to predict the Blue Swallow's global distribution range

\begin{tabular}{lll}
\hline Name & Description & Type \\
\hline Altitudinal roughness & Altitudinal range within each grid cell & Categorical \\
Biomes & Biome type & Categorical \\
Biome richness & Number of biomes in adjacent grid cells & Categorical \\
Ecoregions & Ecoregion type & Categorical \\
Ecoregion richness & Number of ecoregions in adjacent grid cells & Categorical \\
Altitude & SRTM30 digital elevation model & Continuous \\
Bio 2 & Mean diurnal temperature range & Continuous \\
Bio 3 & Isothermality & Continuous \\
Bio 7 & Annual temperature range & Continuous \\
Bio 9 & Mean temperature of driest month & Continuous \\
Bio 12 & Annual precipitation & Continuous \\
Bio 15 & Precipitation seasonality & Continuous \\
Bio 19 & Precipitation of coldest month & Continuous \\
\hline
\end{tabular}


Table S2: The 20 Blue Swallow meta-populations used to assess the viability of the Blue Swallow population throughout its entire breeding range (Figure 1)

\begin{tabular}{|c|c|c|c|c|c|}
\hline $\begin{array}{l}\text { Abbre- } \\
\text { viations }\end{array}$ & Country and metapopulations & Important Bird Areas & $\begin{array}{l}\text { No. of } \\
\text { pairs } \\
\text { in } 2005\end{array}$ & $\begin{array}{l}\text { No. of } \\
\text { pairs } \\
\text { in } 2012\end{array}$ & $\begin{array}{l}\text { Quantityl } \\
\text { Quality }^{\mathrm{a}}\end{array}$ \\
\hline GG & $\begin{array}{l}\text { SOUTH AFRICA } \\
\text { Blyde River Canyon, Graskop } \\
\text { Grasslands and Misty Mountain Natural } \\
\text { Heritage Site }\end{array}$ & $\begin{array}{l}\text { Blyde River Canyon, Graskop } \\
\text { Grasslands, Misty Mountain } \\
\text { Natural Heritage Site }\end{array}$ & 20 & 4 & decreasing \\
\hline BSNHS & $\begin{array}{l}\text { Blue Swallow Natural Heritage Site } \\
\text { KwaZulu-Natal Mist-helt Grasslands }\end{array}$ & $\begin{array}{l}\text { Blue Swallow Natural Heritage } \\
\text { Site }\end{array}$ & 10 & 0 & locally extinct \\
\hline \multirow[t]{2}{*}{ KNMG } & including Impendle Nature Reserve & $\begin{array}{l}\text { KwaZulu-Natal Mistbelt } \\
\text { Grasslands, Impendle Nature } \\
\text { Reserve }\end{array}$ & 54 & 35 & decreasing \\
\hline & SWAZILAND & & & & \\
\hline MNR & Malolotja Nature Reserve & Malolotja Nature Reserve & 12 & 12 & stable? \\
\hline MAM & Mahamba Mountain & Mahamba Mountain & 10 & 0 & locally extinct \\
\hline & $\begin{array}{l}\text { ZIMBABWE AND MOZAMBIQUE } \\
\text { (CHIMANIMANI MOUNTAINS) }\end{array}$ & & & & \\
\hline NM & Nyanga Mountains & Nyanga Mountains & 200 & & decreasing? \\
\hline NLHV & Nyanga lowlands / Honde valley & Nyanga lowlands/Honde Valley & 15 & & decreasing? \\
\hline SF & Stapleford Forest & Stapleford Farm & 10 & & decreasing? \\
\hline $\mathrm{BH}$ & Bvumba Highlands & Bvumba Highlands & 10 & & decreasing? \\
\hline CMM & $\begin{array}{l}\text { Chimanimani Mountains (including } \\
\text { Mozambique section) }\end{array}$ & Chimanimani Mountains & 75 & & decreasing? \\
\hline NNP & $\begin{array}{l}\text { MALAWI, ZAMBIA (NYIKA PLATEAU) } \\
\text { AND MOZAMBIQUE (KIRK RANGE) } \\
\text { Nyika National Park (including Zambian } \\
\text { section) }\end{array}$ & Nyika National Park & 260 & & stable \\
\hline NV & N. Viphya & & 10 & & decreasing? \\
\hline SV & South Viphya Forest Reserve & South Viphya Forest Reserve & 10 & & decreasing? \\
\hline $\mathrm{KR}$ & $\begin{array}{l}\text { Kirk Range (including Mozambique } \\
\text { section) }\end{array}$ & & 30 & 0 & decreasing? \\
\hline MM & Mount Mulanje Forest Reserve & Mount Mulanje Forest Reserve & 10 & & stable \\
\hline UMMHFR & $\begin{array}{l}\text { TANZANIA } \\
\text { S Umalila Mountains and Misuku Hills } \\
\text { Forest Reserve (Malawi) }\end{array}$ & $\begin{array}{l}\text { S Umalila Mountains, Misuku } \\
\text { Hills Forest Reserve }\end{array}$ & 40 & & decreasing? \\
\hline SWTH & $\begin{array}{l}\text { SW part of the highlands in SW } \\
\text { Tanzanina }\end{array}$ & $\begin{array}{l}\text { Kitulo Plateau, Mount Rungwe, } \\
\text { Livingston Mountains Forests, } \\
\text { Njombe Forests }\end{array}$ & 268 & 268 & stable? \\
\hline NETH & NE part of the highlands in SW Tanzania & Udzungwa Mountains & 120 & 120 & stable? \\
\hline UNP & $\begin{array}{l}\text { DRC } \\
\text { Upemba National Park }\end{array}$ & Upemba National Park & 50 & & stable? \\
\hline $\mathrm{MH}$ & Marungu Highlands & Marungu Highlands & 50 & & decreasing? \\
\hline Total & 20 meta-populations & & $\begin{array}{l}1264 \\
\text { pairs }\end{array}$ & $\begin{array}{l}1219 \\
\text { pairs }\end{array}$ & \\
\hline
\end{tabular}


Table S3: Important Bird Areas containing breeding Blue Swallows, currently and in the past, and their estimated Blue Swallow population trends

\begin{tabular}{|c|c|c|c|c|c|}
\hline Country and IBAs & $\begin{array}{l}\text { Level of } \\
\text { protection }\end{array}$ & $\begin{array}{l}\text { Past } \\
(<2000)\end{array}$ & $\begin{array}{l}\text { Current } \\
(2012)\end{array}$ & $\begin{array}{l}\text { Population } \\
\text { trend }\end{array}$ & References \\
\hline \multicolumn{6}{|l|}{ SOUTH AFRICA } \\
\hline $\begin{array}{l}004 \text { Wolkberg Forest Belt } \\
008 \text { Blyde River Canyon } \\
009 \text { Graskop Grasslands } \\
010 \text { Mac Mac Escarpment and Forests } \\
011 \text { Blue Swallow Natural Heritage Site } \\
013 \text { Misty Mountain Natural Heritage Site } \\
057 \text { Impendle Nature Reserve } \\
058 \text { KwaZulu-Natal Mistbelt Grasslands }\end{array}$ & $\begin{array}{l}\text { Strictly } \\
\text { Strictly } \\
\text { Partial } \\
\text { Strictly } \\
\text { Partial } \\
\text { Partial } \\
\text { Strictly } \\
\text { Partial }\end{array}$ & $\begin{array}{l}\text { yes } \\
\text { yes } \\
\text { yes } \\
\text { yes } \\
\text { yes } \\
\text { yes } \\
\text { yes } \\
\text { yes }\end{array}$ & $\begin{array}{l}\text { no } \\
\text { no } \\
\text { yes } \\
\text { no } \\
\text { no } \\
\text { no } \\
\text { yes } \\
\text { yes }\end{array}$ & $\begin{array}{l}\text { locally extinct } \\
\text { locally extinct } \\
\text { decreasing } \\
\text { locally extinct } \\
\text { locally extinct } \\
\text { locally extinct } \\
\text { stable? } \\
\text { decreasing }\end{array}$ & $\begin{array}{l}\text { Barnes (1998) } \\
\text { Barnes (1998) } \\
\text { Barnes (1998) } \\
\text { Barnes (1998) } \\
\text { Barnes (1998) } \\
\text { Barnes (1998) } \\
\text { Barnes (1998) } \\
\text { Barnes (1998) }\end{array}$ \\
\hline \multicolumn{6}{|l|}{ SWAZILAND } \\
\hline $\begin{array}{l}001 \text { Malolotja Nature Reserve } \\
003 \text { Mahamba Mountain }\end{array}$ & $\begin{array}{l}\text { Strictly } \\
\text { Unprotected }\end{array}$ & $\begin{array}{l}\text { yes } \\
\text { yes }\end{array}$ & $\begin{array}{l}\text { Yes } \\
\text { no }\end{array}$ & $\begin{array}{l}\text { stable? } \\
\text { locally extinct }\end{array}$ & $\begin{array}{l}\text { Barnes and Monadjem (2001) } \\
\text { Barnes and Monadjem (2001) }\end{array}$ \\
\hline $\begin{array}{l}\text { ZIMBABWE } \\
001 \text { Nyanga Mountains } \\
002 \text { Nyanga lowlands/Honde Valley } \\
004 \text { Bvumba Highlands } \\
006 \text { Chimanimani Mountains } \\
003 \text { Stapleford Farm }\end{array}$ & $\begin{array}{l}\text { Strictly } \\
\text { Partial } \\
\text { Partial } \\
\text { Strictly } \\
\text { Partial }\end{array}$ & $\begin{array}{l}\text { yes } \\
\text { yes } \\
\text { yes } \\
\text { yes } \\
\text { yes }\end{array}$ & $\begin{array}{l}\text { yes } \\
\text { yes } \\
\text { yes } \\
\text { yes } \\
\text { yes }\end{array}$ & $\begin{array}{l}\text { decreasing } \\
\text { decreasing } \\
\text { decreasing } \\
\text { stable? } \\
\text { decreasing }\end{array}$ & $\begin{array}{l}\text { Childes and Mundy (1998) } \\
\text { Childes and Mundy (1998) } \\
\text { Childes and Mundy (1998) } \\
\text { Childes and Mundy (1998) } \\
\text { Childes and Mundy (1998) }\end{array}$ \\
\hline \multicolumn{6}{|l|}{ MOZAMBIQUE } \\
\hline $\begin{array}{l}\text { MALAWI } \\
001 \text { Misuku Hills Forest Reserve } \\
002 \text { Nyika National Park } \\
006 \text { South Viphya Forest Reserve } \\
018 \text { Mount Mulanje Forest Reserve }\end{array}$ & $\begin{array}{l}\text { Partial } \\
\text { Strictly } \\
\text { Partial } \\
\text { Partial }\end{array}$ & $\begin{array}{l}\text { yes } \\
\text { yes } \\
\text { yes } \\
\text { yes }\end{array}$ & $\begin{array}{l}\text { yes } \\
\text { yes } \\
\text { yes } \\
\text { yes }\end{array}$ & $\begin{array}{l}\text { decreasing } \\
\text { stable } \\
\text { decreasing } \\
\text { decreasing }\end{array}$ & $\begin{array}{l}\text { Dowsett-Lemaire et al. (2001) } \\
\text { Dowsett-Lemaire et al. (2001) } \\
\text { Dowsett-Lemaire et al. (2001) } \\
\text { Dowsett-Lemaire et al. (2001) }\end{array}$ \\
\hline $\begin{array}{l}\text { ZAMBIA } \\
022 \text { Nyika National Park }\end{array}$ & \multicolumn{4}{|c|}{ ZAMBIA } & Leonard (2001) \\
\hline $\begin{array}{l}\text { SW TANZANIA } \\
061 \text { Njombe Forests } \\
065 \text { Mount Rungwe } \\
066 \text { Udzungwa Mountains } \\
069 \text { Umalila Mountains } \\
073 \text { Kitulo Plateau }\end{array}$ & $\begin{array}{l}\text { Partial } \\
\text { Partial } \\
\text { Partial } \\
\text { Partial } \\
\text { Strictly }\end{array}$ & $\begin{array}{l}\text { yes } \\
\text { yes } \\
\text { yes } \\
\text { yes } \\
\text { yes }\end{array}$ & $\begin{array}{l}\text { yes } \\
\text { yes } \\
\text { yes } \\
\text { yes } \\
\text { yes }\end{array}$ & $\begin{array}{l}\text { stable? } \\
\text { stable? } \\
\text { stable? } \\
\text { decreasing } \\
\text { stable? }\end{array}$ & $\begin{array}{l}\text { Baker and Baker (2001) } \\
\text { Baker and Baker (2001) } \\
\text { Baker and Baker (2001) } \\
\text { Baker and Baker (2001) } \\
\text { Baker and Baker (2001) }\end{array}$ \\
\hline $\begin{array}{l}\text { SE DRC } \\
016 \text { Marungu Highlands } \\
017 \text { Upemba National Park }\end{array}$ & $\begin{array}{l}\text { Partial } \\
\text { Strictly }\end{array}$ & $\begin{array}{l}\text { yes } \\
\text { yes }\end{array}$ & $\begin{array}{l}\text { yes } \\
\text { yes }\end{array}$ & $\begin{array}{l}\text { decreasing } \\
\text { stable? }\end{array}$ & $\begin{array}{l}\text { Demey and Louette (2001) } \\
\text { Demey and Louette (2001) }\end{array}$ \\
\hline$n=26$ & & yes: 26 & $\begin{array}{l}\text { yes: } 20 \text {, } \\
\text { no: } 6\end{array}$ & $\begin{array}{l}\text { locally } \\
\text { extinct: } 6 \\
\text { decreasing: } \\
10 \\
\text { stable?: } 10\end{array}$ & \\
\hline
\end{tabular}

\section{References}

Baker NE, Baker LM. 2001. Tanzania. In: Fishpool LDC, Evans MI (eds), Important Bird Areas of Africa and associated islands: priority sites for conservation. Bird Conservation Series no. 11. Newbury: Pisces Publications; Cambridge: BirdLife International. pp 897-945.

Barnes KN (ed.) 1998. The Important Bird Areas of southern Africa. Johannesburg: BirdLife South Africa.

Barnes KN, Monadjem A. 2001. Swaziland. In: Fishpool LDC, Evans M. (eds), Important Bird Areas of Africa and associated islands: priority sites for conservation. Bird Conservation Series no. 11. Newbury: Pisces Publications; Cambridge: BirdLife International. pp 891-895.

Childes SL, Mundy PJ. 1998. Important Bird Areas in Zimbabwe. In: Barnes KN (ed.), The Important Bird Areas of southern Africa. Johannesburg: BirdLife South Africa. pp 1025-1042.

Demey R, Louette M. 2001. Democratic Republic of Congo. In: Fishpool LDC, Evans MI (eds), Important Bird Areas of Africa and associated islands: priority sites for conservation. Bird Conservation Series no. 11. Newbury: Pisces Publications; Cambridge: BirdLife International. pp 199-218. 
Dowsett-Lemaire F, Dowsett RJ, Dyer M. 2001. Malawi. In: Fishpool LDC, Evans MI (eds), Important Bird Areas of Africa and associated islands: priority sites for conservation. Bird Conservation Series no. 11. Newbury: Pisces Publications; Cambridge: BirdLife International. pp 539-555.

Leonard PM. 2001. Zambia. In: Fishpool LDC, Evans MI (eds), Important Bird Areas of Africa and associated islands: priority sites for conservation. Bird Conservation Series no. 11. Newbury: Pisces Publications; Cambridge: BirdLife International. pp 1005-1024.

Parker V. 2001. Mozambique. In: Fishpool LDC, Evans MI (eds), Important Bird Areas of Africa and associated islands: priority sites for conservation. Bird Conservation Series no. 11. Newbury: Pisces Publications; Cambridge: BirdLife International. pp 627-638. 
Table S4: Important Bird Areas containing non-breeding Blue Swallows, currently and in the past, and their estimated Blue Swallow population trends

\begin{tabular}{|c|c|c|c|c|c|}
\hline Country and IBAs & $\begin{array}{l}\text { Level of } \\
\text { protection }\end{array}$ & $\begin{array}{l}\text { Past } \\
(<2000)\end{array}$ & $\begin{array}{l}\text { Current } \\
(2012)\end{array}$ & $\begin{array}{l}\text { Population } \\
\text { trend }\end{array}$ & References \\
\hline \multicolumn{6}{|l|}{ NW TANZANIA } \\
\hline 009 Serengeti National Park & Strictly & no & yes & expanding? & Baker and Baker (2001) \\
\hline 075 Minziro Forest Reserve & Strictly & yes & yes & stable? & Baker and Baker (2001) \\
\hline \multicolumn{6}{|l|}{ NE DRC } \\
\hline 007 Lendu Plateau & Partial & yes & yes & decreasing & Demey and Louette (2001) \\
\hline \multicolumn{6}{|l|}{ UGANDA } \\
\hline 012 Mabira Forest & Partial & yes & no & locally extinct & Byaruhanga et al. (2001) \\
\hline 013 Sango Bay & Partial & yes & yes & decreasing & Byaruhanga et al. (2001) \\
\hline 016 Nabugabo Wetlands & Partial & yes & yes & stable? & Byaruhanga et al. (2001) \\
\hline 017 Mabamba Bay & Partial & yes & yes & decreasing & Byaruhanga et al. (2001) \\
\hline 028 Mount Elgon National Park & Strictly & yes & no & locally extinct & Byaruhanga et al. (2001) \\
\hline \multicolumn{6}{|l|}{ KENYA } \\
\hline 028 Mount Elgon National Park & Strictly & yes & no & locally extinct & Bennun and Njoroge (2001) \\
\hline 040 Ruma National Park & Strictly & yes & yes & stable? & Bennun and Njoroge (2001) \\
\hline 050 Masai Mara & Strictly & no & yes & expanding? & Kennedy AS pers. comm. (2012) \\
\hline 057 Busia Grasslands & Partial & yes & no & locally extinct & Bennun and Njoroge (2001) \\
\hline $\mathrm{n}=11$ & & $\begin{array}{l}\text { yes: } 9 \\
\text { no: } 2\end{array}$ & $\begin{array}{l}\text { yes: } 8 \\
\text { no: } 3\end{array}$ & $\begin{array}{l}\text { locally extinct: } \\
3 \\
\text { decreasing: } 3 \\
\text { stable?: } 3 \\
\text { expanding?: } 2\end{array}$ & \\
\hline
\end{tabular}

\section{References}

Baker NE, Baker LM. 2001. Tanzania. In: Fishpool LDC, Evans MI (eds), Important Bird Areas of Africa and associated islands: priority sites for conservation. Bird Conservation Series no. 11. Newbury: Pisces Publications; Cambridge: BirdLife International. pp 897-945.

Bennun L, Njoroge P. 2001. Kenya. 2001. In: Fishpool LDC, Evans MI (eds), Important Bird Areas of Africa and associated islands: priority sites for conservation. Bird Conservation Series no. 11. Newbury: Pisces Publications; Cambridge: BirdLife International. pp 411-464.

Byaruhanga A, Kasoma P, Pomeroy, D. 2001. Uganda. In: Fishpool LDC, Evans MI (eds), Important Bird Areas of Africa and associated islands: priority sites for conservation. Bird Conservation Series no. 11. Newbury: Pisces Publications; Cambridge: BirdLife International. pp 975-1003.

Demey R, Louette M. 2001. Democratic Republic of Congo. In: Fishpool LDC, Evans MI (eds), Important Bird Areas of Africa and associated islands: priority sites for conservation. Bird Conservation Series no. 11. Newbury: Pisces Publications; Cambridge: BirdLife International. pp 199-218. 
Table S5: The criteria (IUCN 2001) used to assess the conservation status of Blue Swallows per country. Adapted from Evans (in press) and Combrink and Little (2012). The criteria according to which the birds per country qualify in the highest of the three conservation statuses are indicated in bold

\begin{tabular}{|c|c|c|c|c|c|c|c|c|}
\hline $\begin{array}{l}\text { Conservation status per } \\
\text { country }\end{array}$ & $\begin{array}{l}\text { Total no. of } \\
\text { individuals }\end{array}$ & $\begin{array}{l}\text { Largest no. of } \\
\text { individuals in } \\
\text { a single } \\
\text { continuous } \\
\text { area }\end{array}$ & $\begin{array}{l}\mathrm{Br} / \mathrm{NBr} \\
\text { Range }\end{array}$ & A & B & C & D & $\mathbf{E}$ \\
\hline \multicolumn{9}{|c|}{ Critically Endangered $(n=5)$} \\
\hline South Africa & 74 & 70 & $\mathrm{Br}$ & A2(a) $(>50 \%)$ & $\begin{array}{l}\text { B1 }\left(<5000 \mathrm{~km}^{2}\right) \\
\text { B2 }\left(<500 \mathrm{~km}^{2}\right) \\
\text { B a,b (i, ii, iii, iv, v) }\end{array}$ & $\begin{array}{l}\text { C }(<250) \\
\text { C1 }(20 \% \text { in } 5 \text { years }) \\
\text { C2 a (l) }(<50)\end{array}$ & $\mathrm{D} 1(<250)$ & $E(>50 \%$ in 10 years) \\
\hline Swaziland & 24 & 24 & $\mathrm{Br}$ & A2(a) (> 50\%) & $\begin{array}{l}\text { B1 }\left(<100 \mathrm{~km}^{2}\right) \\
\text { B2 }\left(<10 \mathrm{~km}^{2}\right) \\
\text { B a,b (i, ii, iii, iv, v) }\end{array}$ & $\begin{array}{l}\text { C }(<250) \\
\text { C1 (20\% in } 5 \text { years) } \\
\text { C2 a (i) }(<50)\end{array}$ & $\mathrm{D1}(<50)$ & $E(>50 \%$ in 10 years) \\
\hline Zambia & 20 & 20 & $\mathrm{Br}$ & & $\begin{array}{l}\text { B1 }\left(<100 \mathrm{~km}^{2}\right) \\
\text { B2 }\left(<10 \mathrm{~km}^{2}\right) \\
\text { B a, b(iii) }\end{array}$ & $\begin{array}{l}C(<250) \\
C 2 \text { a (i) }(<50)\end{array}$ & $\mathrm{D} 1(<50)$ & $E(>10 \%$ in 100 years) \\
\hline Mozambique & 60 & 20 & $\mathrm{Br}$ & & $\begin{array}{l}\text { B1 }\left(<5000 \mathrm{~km}^{2}\right) \\
\text { B2 }\left(<500 \mathrm{~km}^{2}\right) \\
\text { B a, b(i) }\end{array}$ & $\begin{array}{l}C(<250) \\
C 2 a(i)(<50)\end{array}$ & $\mathrm{D} 1(<250)$ & $E(>10 \%$ in 100 years) \\
\hline Kenya & 540 & 450 & $\mathrm{NBr}$ & & $\begin{array}{l}\text { B1 }\left(<100 \mathrm{~km}^{2}\right) \\
\mathrm{B} \mathrm{a}, \mathrm{b}(\mathrm{i}, \mathrm{iii})\end{array}$ & $\begin{array}{l}C(<2500) \\
C 2 a(i)(<1000)\end{array}$ & $\mathrm{D} 1(<250)$ & $E(>10 \%$ in 100 years) \\
\hline \multicolumn{9}{|l|}{ Endangered $(n=2)$} \\
\hline DRC & 200 & 100 & $\mathrm{Br}$ and $\mathrm{NBr}$ & & $\begin{array}{l}\text { B1 }\left(<20000 \mathrm{~km}^{2}\right) \\
\text { B b(i, iii) }\end{array}$ & $\begin{array}{l}\mathrm{C}(<250) \\
\mathrm{C} 2 \mathrm{a}(\mathrm{i}, \mathrm{ii})(<250)(90-100 \%)\end{array}$ & D1 $(<250)$ & $E(>10 \%$ in 100 years) \\
\hline Uganda & 1295 & 430 & $\mathrm{NBr}$ & & $\begin{array}{l}\text { B1 }\left(<5000 \mathrm{~km}^{2}\right) \\
\text { B a, b(ii, iii) }\end{array}$ & $\begin{array}{l}C(<2500) \\
C 2 a(i)(<1000)\end{array}$ & $\mathrm{D} 1(<1000)$ & \\
\hline \multicolumn{9}{|l|}{ Vulnerable $(n=3)$} \\
\hline Tanzania & 560 & 360 & $\mathrm{Br}$ and $\mathrm{NBr}$ & & $\begin{array}{l}\text { B1 }\left(<20000 \mathrm{~km}^{2}\right) \\
\text { B b(i, iii) }\end{array}$ & $\begin{array}{l}C(<2500) \\
C 2 \mathrm{a}(\mathrm{i})(<1000)\end{array}$ & $\mathrm{D} 1(<1000)$ & \\
\hline Zimbabwe & 620 & 500 & $\mathrm{Br}$ & & $\begin{array}{l}\text { B1 }\left(<20000 \mathrm{~km}^{2}\right) \\
\text { B a, b(i, iii, iv) }\end{array}$ & $\begin{array}{l}C(<2500) \\
C 2 \mathrm{a}(\mathrm{i})(<1000)\end{array}$ & $\mathrm{D} 1(<1000)$ & \\
\hline Malawi & 600 & 520 & $\mathrm{Br}$ & & $\begin{array}{l}\text { B1 }\left(<20000 \mathrm{~km}^{2}\right) \\
\text { B2 }\left(<2000 \mathrm{~km}^{2}\right) \\
\text { B a, b(i, ii,iii, v) }\end{array}$ & $\begin{array}{l}C(<2500) \\
C 2 a(i)(<1000)\end{array}$ & $\mathrm{D} 1(<1000)$ & \\
\hline
\end{tabular}

\section{References}

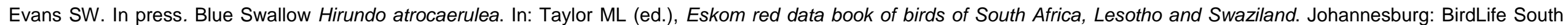
Africa.

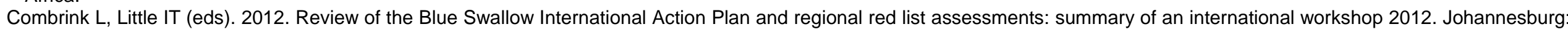
Endangered Wildlife Trust. 


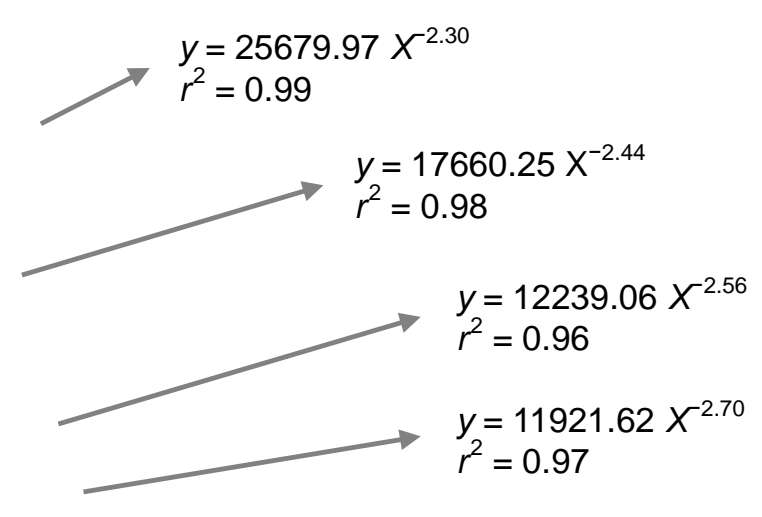

Figure S1: Sensitivity of meta-population size to the number of meta-populations and to decreases in adult and first year mortality and an increase in breeding longevity. Legend: $\boldsymbol{m}=$ baseline: adult mortality $40 \%$, longevity 4 years, first year mortality $65 \%$, adult mortality $35 \%, \boldsymbol{\nabla}=$ breeding longevity 6 years, $\boldsymbol{\Delta}=$ first year mortality $60 \%$. 


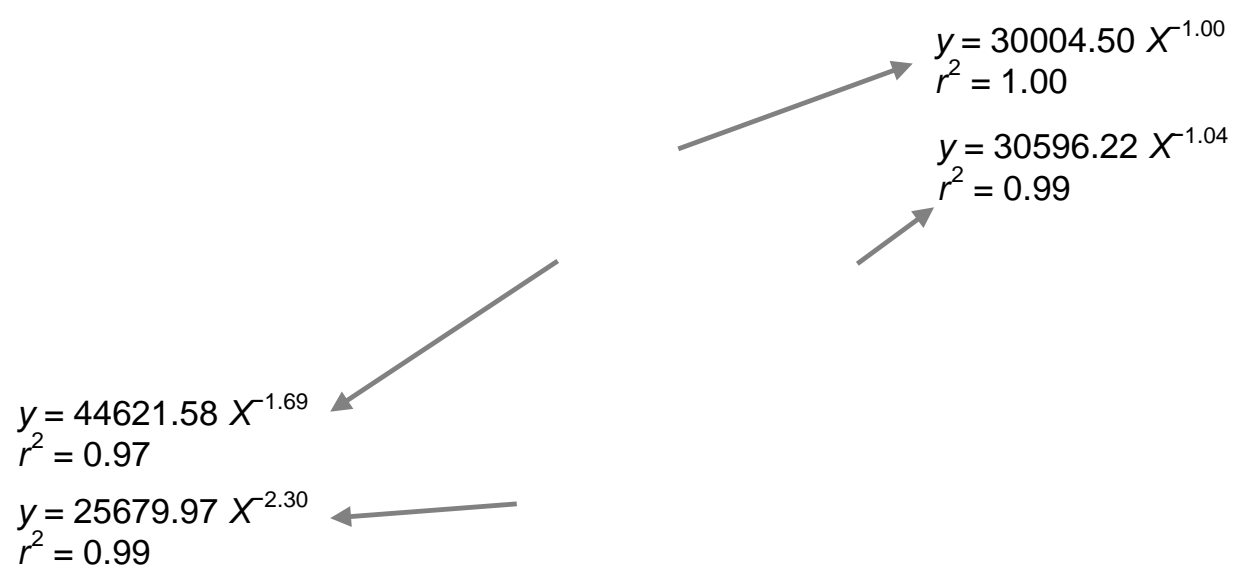

Figure S2: Sensitivity of meta-population size to the number of meta-populations and to increases in adult and first year mortality and a decrease in breeding longevity. Legend: $\mathbf{m}$ = baseline: adult mortality 40\%, longevity 4 years, first year mortality $65 \%$, adult mortality $35 \%, \boldsymbol{\nabla}=$ breeding longevity 6 years, $\boldsymbol{\Lambda}=$ first year mortality $60 \%$. 
Figure S3: Sensitivity of the stochastic intrinsic rate of natural population change $(r)$ and the probability of extinction of the Blue Swallow population to changes to certain variables.

Figure S4: Each meta-populations probability of extinction, arranged from the highest to the lowest, along with each meta-populations predicted stochastic rate of population increase and initial population size. See Table 2 for an explanation of the abbreviations ( $X$ axis). 


\section{Supplementary Information}

\section{Appendix 1}

Blue Swallow baseline Vortex model variables

VORTEX 9.99 -- simulation of population dynamics

Frì Mar 28 14:16:37 2014

20 population(s) simulated for 100 years, 1000 iterations

Each simulation year is 365 days duration.

Extinction is defined as no animals of one or both sexes.

No inbreeding depression

Minimum age at dispersal is 1 .

Maximum age at dispersal is 1 .

Both females and males disperse.

Percent survival during dispersal $=95$

Dispersal rate matrix (rows are source populations; columns are recipient populations):

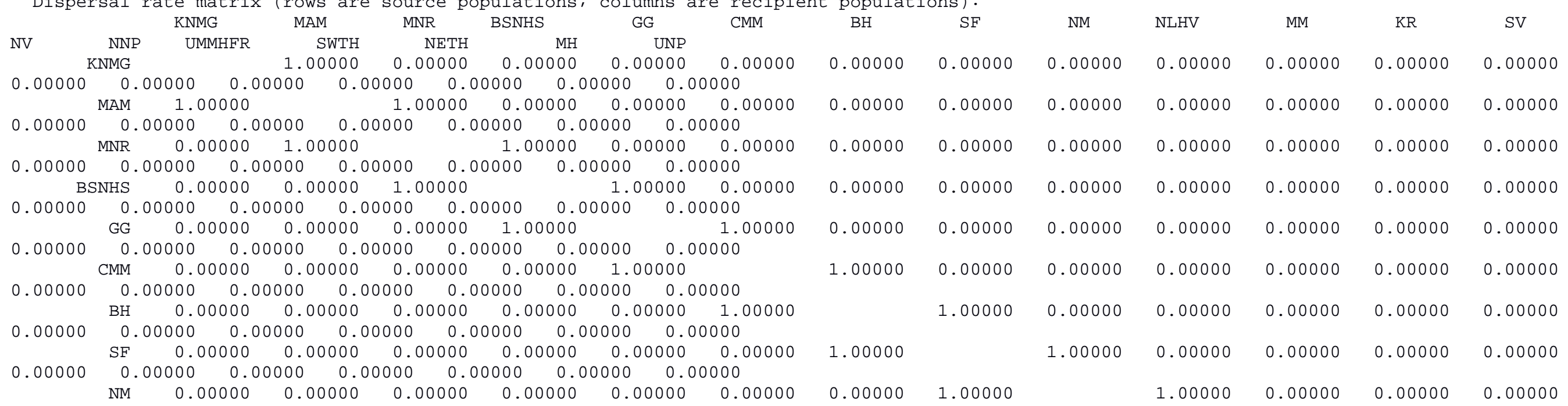


$\begin{array}{lllllll}0.00000 & 0.00000 & 0.00000 & 0.00000 & 0.00000 & 0.00000 & 0.00000\end{array}$

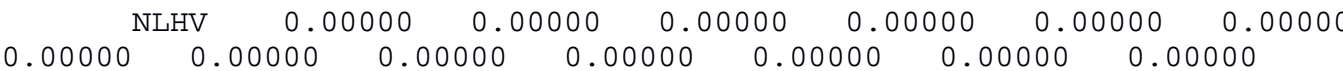

$\begin{array}{ccccccc}0.000 \odot \odot & 0.000 \odot \odot & 0.000 \odot \odot & 0.0000 \odot & 0.000 \odot \odot & 0.000 \odot \odot & 0.0000 \odot\end{array}$

$\odot .0 \odot \odot \odot \odot \quad \odot . ๑ \odot \odot \odot \odot$

$\odot . \odot \odot \odot \odot \odot$

1.00000

$\begin{array}{lllllll}K R & 0.00000 & 0.00000 & 0.00000 & 0.00000 & 0.00000 & 0.00000\end{array}$

$\odot .0000 \odot$

$\odot .0000 \odot$

0.00000

$\odot .0000 \odot$

1.00000

1.00000

SV $0.0000 \odot \quad 0.0000 \odot \quad 0.0000 \odot \quad 0.0000 \odot \quad 0.0000 \odot \quad 0.0000 \odot$

$\odot .0000 \odot \quad \odot .0000 \odot$

$\odot .00000$

$\odot .000 \odot \odot$

$\odot .00000$

$1.0000 \odot$

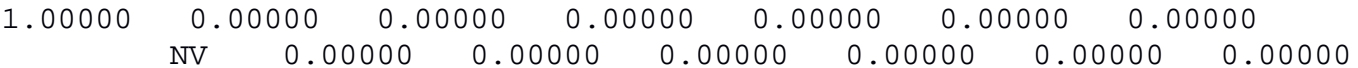

$\odot .0000 \odot \quad \odot .0000 \odot$

0.00000

$\odot .00000$

$\odot .00000$

$\odot . \odot \odot \odot \odot \odot$

1.00000

$1.00 \odot \odot \odot$ $\begin{array}{lllll}0.00000 & 0.00000 & 0.00000 & 0.00000 & 0.00000\end{array}$

$\begin{array}{llllll}1.00000 & 0.00000 & 0.00000 & 0.00000 & 0.00000\end{array}$

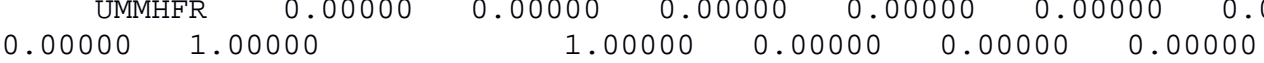

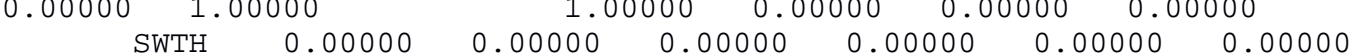

$\odot .0 \odot \odot \odot \odot$

$\odot .000 \odot \odot$

$\odot .0000 \odot$

$\odot .0 \odot \odot \odot \odot$

$\odot .000 \odot \odot$

$\odot . \odot \odot \odot \odot \odot$

$\odot .00000$

$0.00000 \quad 0.00000$

$\odot .00000$

$\odot .00000$

$\odot .00000$

$\odot .0000 \odot$

$\odot .00000$

$\odot .00000 \quad 0.00000 \quad 1.00000$ $\begin{array}{lll}1.0000 \odot & 0.0000 \odot \quad 0.0000 \odot\end{array}$

$\odot .00000 \quad 0.00000$

$\odot .00000$

$\odot . \odot \odot \odot \odot \odot$

$\odot . \odot \odot \odot \odot \odot$

0.00000

$\odot .00000$

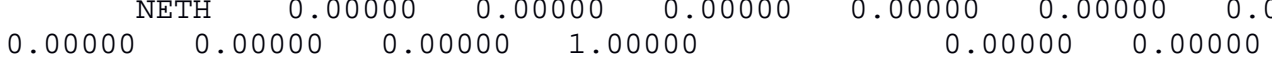

$\odot .0000 \odot \quad 0.0000 \odot$

$\odot .00000$

$\odot . \odot \odot \odot \odot \odot$

$\odot .00000$

$\odot .00000$

$\odot .00000$

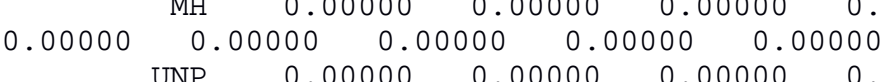

$00000 \quad 0.00000 \quad 0.00000$

$\odot . \odot \odot \odot \odot \odot$

$\odot . \odot 000 \odot$

$\odot .00000$

$\odot . \odot \odot \odot \odot \odot$

$\odot .0000 \odot$

$\odot .00000$

$\odot .0000 \odot$

$\begin{array}{ccccccc}0.000 \odot \odot & 0.000 \odot \odot & 0.000 \odot \odot & 0.000 \odot \odot & 0.000 \odot \odot & 1.000 \odot \odot\end{array}$

EV in reproduction and mortality will be concordant.

Correlation of EV among populations $=0.500000$

First age of reproduction for females: 1 for males: 1

Maximum breeding age (senescence): 4

Sex ratio at birth (percent males): 50

\section{Population 1: KNMG}

Polygynous mating;

$\%$ of adult males in the breeding pool $=37.6$

$\%$ adult females breeding $=100$

$\mathrm{EV}$ in \% adult females breeding: $\mathrm{SD}=45$

Distribution of number of separately sired broods produced by a female in a year ...

$\odot . \odot \odot$ percent of females produce $\odot$ broods (litters, clutches) in an average year

60.00 percent of females produce 1 broods (litters, clutches) in an average year

40.00 percent of females produce 2 broods (litters, clutches) in an average year

of those females producing progeny, ...

15.00 percent of females produce 1 progeny in an average year

40.00 percent of females produce 2 progeny in an average year

45. 00 percent of females produce 3 progeny in an average year 
$\%$ mortality of females between ages $\odot$ and $1=65$

EV in \% mortality: SD $=15$

$\%$ mortality of adult females $(1<=$ age $<=4)=40$

EV in \% mortality: SD $=15$

$\%$ mortality of males between ages $\odot$ and $1=65$

EV in \% mortality: SD $=15$

$\%$ mortality of adult males $(1<=$ age $<=4)=40$

EV in \% mortality: SD $=15$

EVs may be adjusted to closest values possible for binomial distribution.

Initial size of KNMG:

112

(set to reflect stable age distribution)

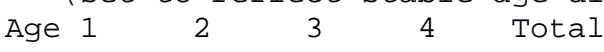

$\begin{array}{llllll}28 & 15 & 9 & 4 & 56 & \text { Males }\end{array}$

$\begin{array}{llllll}28 & 15 & 9 & 4 & 56 & \text { Females }\end{array}$

Carrying capacity $=112$

with a 0.461 percent increase for $\odot$ years.

EV in Carrying capacity $=0$

Population 2: MAM

Polygynous mating;

$\%$ of adult males in the breeding pool $=37.6$

$\%$ adult females breeding $=100$

EV in \% adult females breeding: $S D=45$

Distribution of number of separately sired broods produced by a female in a year ...

$\odot . \odot \odot$ percent of females produce $\odot$ broods (litters, clutches) in an average year

60.00 percent of females produce 1 broods (litters, clutches) in an average year

40.00 percent of females produce 2 broods (litters, clutches) in an average year

of those females producing progeny, ...

15.00 percent of females produce 1 progeny in an average year

40.0๑ percent of females produce 2 progeny in an average year

45.00 percent of females produce 3 progeny in an average year

$\%$ mortality of females between ages $\odot$ and $1=65$

EV in \% mortality: SD $=15$

$\%$ mortality of adult females $(1<=$ age $<=4)=40$

EV in \% mortality: $S D=15$

$\%$ mortality of males between ages $\odot$ and $1=65$

EV in \% mortality: SD $=15$

$\%$ mortality of adult males $(1<=$ age $<=4)=4 \odot$

EV in \% mortality: SD $=15$

EVs may be adjusted to closest values possible for binomial distribution. 
Initial size of MAM:

(set to reflect stable age distribution)

Age $\begin{array}{lllll}1 & 2 & 3 & 4 & \text { Total }\end{array}$

$\begin{array}{lllll}5 & 3 & 1 & 1 & 10 \text { Males }\end{array}$

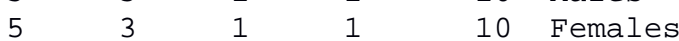

Carrying capacity $=20$

with a 0.461 percent increase for $\odot$ years.

EV in Carrying capacity $=0$

Population 3: MNR

Polygynous mating;

$\%$ of adult males in the breeding pool $=37.6$

$\%$ adult females breeding $=100$

EV in \% adult females breeding: SD $=45$

Distribution of number of separately sired broods produced by a female in a year ... $\odot .0 \odot$ percent of females produce $\odot$ broods (litters, clutches) in an average year

60.00 percent of females produce 1 broods (litters, clutches) in an average year

$40.0 \odot$ percent of females produce 2 broods (litters, clutches) in an average year

of those females producing progeny, ...

15. 00 percent of females produce 1 progeny in an average year

40.00 percent of females produce 2 progeny in an average year

45.00 percent of females produce 3 progeny in an average year

$\%$ mortality of females between ages $\odot$ and $1=65$

EV in \% mortality: SD $=15$

$\%$ mortality of adult females $(1<=$ age $<=4)=40$

EV in \% mortality: $S D=15$

$\%$ mortality of males between ages $\odot$ and $1=65$

EV in \% mortality: SD = 15

$\%$ mortality of adult males $(1<=$ age $<=4)=40$

EV in \% mortality: $S D=15$

EVs may be adjusted to closest values possible for binomial distribution.

Initial size of MNR:

24

(set to reflect stable age distribution)

Age 1

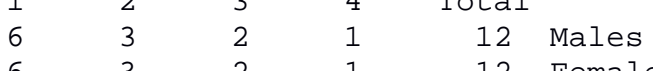

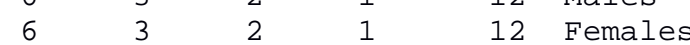

Carrying capacity $=24$

with a $\odot .461$ percent increase for $\odot$ years.

$\mathrm{EV}$ in Carrying capacity $=0$ 
Population 4: BSNHS

Polygynous mating;

$\%$ of adult males in the breeding pool $=37.6$

$\%$ adult females breeding $=100$

$\mathrm{EV}$ in \% adult females breeding: SD $=45$

Distribution of number of separately sired broods produced by a female in a year ...

$\odot . \odot \odot$ percent of females produce $\odot$ broods (litters, clutches) in an average year

60.00 percent of females produce 1 broods (litters, clutches) in an average year

40.0๑ percent of females produce 2 broods (litters, clutches) in an average year

of those females producing progeny, ...

15.00 percent of females produce 1 progeny in an average year

40.00 percent of females produce 2 progeny in an average year

45.00 percent of females produce 3 progeny in an average year

$\%$ mortality of females between ages 0 and $1=65$

$\mathrm{EV}$ in \% mortality: $\mathrm{SD}=15$

$\%$ mortality of adult females $(1<=$ age $<=4)=40$

EV in \% mortality: $S D=15$

$\%$ mortality of males between ages $\odot$ and $1=65$

EV in \% mortality: SD $=15$

$\%$ mortality of adult males $(1<=$ age $<=4)=40$

$\mathrm{EV}$ in \% mortality: $\mathrm{SD}=15$

EVs may be adjusted to closest values possible for binomial distribution.

Initial size of BSNHS:

20

(set to reflect stable age distribution)

Age 1

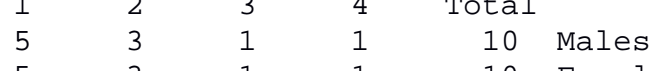

$\begin{array}{llllll}5 & 3 & 1 & 1 & 10 & \text { Females }\end{array}$

Carrying capacity $=20$

with a $\odot .461$ percent increase for $\odot$ years.

$\mathrm{EV}$ in Carrying capacity $=0$

Population 5: GG

Polygynous mating;

$\%$ of adult males in the breeding pool $=37.6$

$\%$ adult females breeding $=100$

$\mathrm{EV}$ in \% adult females breeding: $\mathrm{SD}=45$ 
Distribution of number of separately sired broods produced by a female in a year...

$\odot .0 \odot$ percent of females produce $\odot$ broods (litters, clutches) in an average year

60.00 percent of females produce 1 broods (litters, clutches) in an average year

40.00 percent of females produce 2 broods (litters, clutches) in an average year

of those females producing progeny, ...

15.00 percent of females produce 1 progeny in an average year

40. $0 \odot$ percent of females produce 2 progeny in an average year

45.00 percent of females produce 3 progeny in an average year

$\%$ mortality of females between ages $\odot$ and $1=65$

EV in \% mortality: SD = 15

$\%$ mortality of adult females $(1<=$ age $<=4)=40$

EV in \% mortality: $S D=15$

$\%$ mortality of males between ages $\odot$ and $1=65$

EV in \% mortality: SD $=15$

$\%$ mortality of adult males $(1<=$ age $<=4)=40$

$\mathrm{EV}$ in \% mortality: $\mathrm{SD}=15$

EVs may be adjusted to closest values possible for binomial distribution.

Initial size of $\mathrm{GG}$ :

(set to reflect stable age distribution)

Age $\begin{array}{llccc}1 & 2 & 3 & 4 & \text { Total }\end{array}$

$\begin{array}{llllll}10 & 6 & 2 & 2 & 20 & \text { Males }\end{array}$

Carrying capacity $=40$

with a $\odot .461$ percent increase for $\odot$ years.

$\mathrm{EV}$ in Carrying capacity $=0$

Population 6: CMM

Polygynous mating;

$\%$ of adult males in the breeding pool $=37.6$

$\%$ adult females breeding $=100$

EV in \% adult females breeding: SD $=45$

Distribution of number of separately sired broods produced by a female in a year...

$\odot .0 \odot$ percent of females produce $\odot$ broods (litters, clutches) in an average year

$60.0 \odot$ percent of females produce 1 broods (litters, clutches) in an average year

$40.0 \odot$ percent of females produce 2 broods (litters, clutches) in an average year

of those females producing progeny, ...

15.00 percent of females produce 1 progeny in an average year

40.00 percent of females produce 2 progeny in an average year

45.00 percent of females produce 3 progeny in an average year 
$\%$ mortality of females between ages $\odot$ and $1=65$

EV in \% mortality: SD $=15$

$\%$ mortality of adult females $(1<=$ age $<=4)=40$

EV in \% mortality: SD $=15$

$\%$ mortality of males between ages $\odot$ and $1=65$

EV in \% mortality: SD $=15$

$\%$ mortality of adult males $(1<=$ age $<=4)=40$

EV in \% mortality: SD $=15$

EVs may be adjusted to closest values possible for binomial distribution.

Initial size of CMM:

150

(set to reflect stable age distribution)

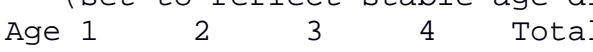

$\begin{array}{llllll}38 & 20 & 11 & 6 & 75 & \text { Males }\end{array}$

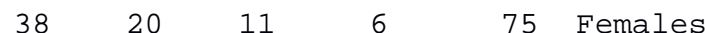

Carrying capacity $=150$

with a 0.461 percent increase for $\odot$ years.

EV in Carrying capacity $=0$

Population 7: BH

Polygynous mating;

$\%$ of adult males in the breeding pool $=37.6$

$\%$ adult females breeding $=100$

EV in \% adult females breeding: SD $=45$

Distribution of number of separately sired broods produced by a female in a year ...

$\odot . \odot \odot$ percent of females produce $\odot$ broods (litters, clutches) in an average year

60.00 percent of females produce 1 broods (litters, clutches) in an average year

40.00 percent of females produce 2 broods (litters, clutches) in an average year

of those females producing progeny, ...

15.00 percent of females produce 1 progeny in an average year

40.0๑ percent of females produce 2 progeny in an average year

45.00 percent of females produce 3 progeny in an average year

$\%$ mortality of females between ages $\odot$ and $1=65$

EV in \% mortality: SD $=15$

$\%$ mortality of adult females $(1<=$ age $<=4)=40$

EV in \% mortality: $S D=15$

$\%$ mortality of males between ages $\odot$ and $1=65$

EV in \% mortality: SD $=15$

$\%$ mortality of adult males $(1<=$ age $<=4)=40$

EV in \% mortality: SD $=15$

EVs may be adjusted to closest values possible for binomial distribution. 
Initial size of $\mathrm{BH}$ :

(set to reflect stable age distribution)

Age $1 \quad 2 \quad 3 \quad 4 \quad$ Tota

$\begin{array}{llllll}5 & 3 & 1 & 1 & 10 & \text { Males }\end{array}$

$\begin{array}{llll}3 & 1 & 1 & 10\end{array}$

Carrying capacity $=20$

with a 0.461 percent increase for $\odot$ years.

EV in Carrying capacity $=0$

Population 8: SF

Polygynous mating;

$\%$ of adult males in the breeding pool $=37.6$

$\%$ adult females breeding $=100$

$\mathrm{EV}$ in \% adult females breeding: $\mathrm{SD}=45$

Distribution of number of separately sired broods produced by a female in a year ... $\odot .0 \odot$ percent of females produce $\odot$ broods (litters, clutches) in an average year

60.00 percent of females produce 1 broods (litters, clutches) in an average year

$40.0 \odot$ percent of females produce 2 broods (litters, clutches) in an average year

of those females producing progeny, ...

15.00 percent of females produce 1 progeny in an average year

40.00 percent of females produce 2 progeny in an average year

45.00 percent of females produce 3 progeny in an average year

$\%$ mortality of females between ages $\odot$ and $1=65$

EV in \% mortality: SD $=15$

$\%$ mortality of adult females $(1<=$ age $<=4)=40$

EV in \% mortality: $\mathrm{SD}=15$

$\%$ mortality of males between ages $\odot$ and $1=65$

EV in \% mortality: SD $=15$

$\%$ mortality of adult males $(1<=$ age $<=4)=40$

EV in \% mortality: $S D=15$

EVs may be adjusted to closest values possible for binomial distribution.

Initial size of SF:

(set to reflect stable age distribution)

Age 1

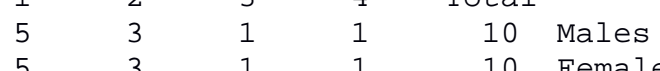

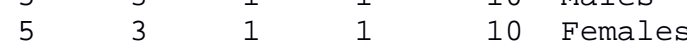

Carrying capacity $=20$

with a $\odot .461$ percent increase for $\odot$ years.

$\mathrm{EV}$ in Carrying capacity $=0$ 
Population 9: NM

Polygynous mating:

$\%$ of adult males in the breeding pool $=37.6$

$\%$ adult females breeding $=100$

$\mathrm{EV}$ in \% adult females breeding: $\mathrm{SD}=45$

Distribution of number of separately sired broods produced by a female in a year...

$\odot .00$ percent of females produce $\odot$ broods (litters, clutches) in an average year

60.00 percent of females produce 1 broods (litters, clutches) in an average year

$40.0 \odot$ percent of females produce 2 broods (litters, clutches) in an average year

of those females producing progeny, ...

15.00 percent of females produce 1 progeny in an average year

$40.0 \odot$ percent of females produce 2 progeny in an average year

45. 00 percent of females produce 3 progeny in an average year

$\%$ mortality of females between ages $\odot$ and $1=65$

$\mathrm{EV}$ in \% mortality: $\mathrm{SD}=15$

$\%$ mortality of adult females $(1<=$ age $<=4)=40$

EV in \% mortality: SD $=15$

$\%$ mortality of males between ages $\odot$ and $1=65$

EV in \% mortality: SD = 15

$\%$ mortality of adult males $(1<=$ age $<=4)=40$

EV in \% mortality: $\mathrm{SD}=15$

EVs may be adjusted to closest values possible for binomial distribution.

Initial size of NM:

400

(set to reflect stable age distribution)

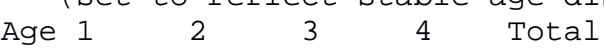

$\begin{array}{lllll}101 & 54 & 29 & 16 & 200 \\ 101 & 54 & 29 & 16 & 200\end{array}$

$\begin{array}{llllll}101 & 54 & 29 & 16 & 200 & \text { Females }\end{array}$

Carrying capacity $=400$

with a $\odot .461$ percent increase for $\odot$ years.

$\mathrm{EV}$ in Carrying capacity $=0$

Population 10: NLHV

Polygynous mating;

$\%$ of adult males in the breeding pool $=37.6$

$\%$ adult females breeding $=100$

$\mathrm{EV}$ in \% adult females breeding: $\mathrm{SD}=45$ 
Distribution of number of separately sired broods produced by a female in a year...

$\odot .0 \odot$ percent of females produce $\odot$ broods (litters, clutches) in an average year

60.00 percent of females produce 1 broods (litters, clutches) in an average year

40.00 percent of females produce 2 broods (litters, clutches) in an average year

of those females producing progeny, ...

15.00 percent of females produce 1 progeny in an average year

40. $0 \odot$ percent of females produce 2 progeny in an average year

45.00 percent of females produce 3 progeny in an average year

$\%$ mortality of females between ages $\odot$ and $1=65$

EV in \% mortality: SD = 15

$\%$ mortality of adult females $(1<=$ age $<=4)=40$

EV in \% mortality: $S D=15$

$\%$ mortality of males between ages $\odot$ and $1=65$

EV in \% mortality: SD $=15$

$\%$ mortality of adult males $(1<=$ age $<=4)=40$

$\mathrm{EV}$ in \% mortality: $\mathrm{SD}=15$

EVs may be adjusted to closest values possible for binomial distribution.

Initial size of NLHV:

(set to reflect stable age distribution)

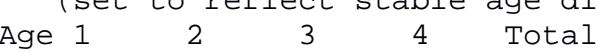

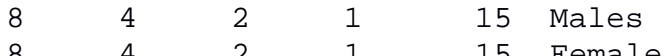

Carrying capacity $=30$

with a $\odot .461$ percent increase for $\odot$ years.

$\mathrm{EV}$ in Carrying capacity $=0$

Population 11: MM

Polygynous mating;

$\%$ of adult males in the breeding pool $=37.6$

$\%$ adult females breeding $=100$

$\mathrm{EV}$ in \% adult females breeding: $\mathrm{SD}=45$

Distribution of number of separately sired broods produced by a female in a year ...

$\odot . \odot \odot$ percent of females produce $\odot$ broods (litters, clutches) in an average year

60.00 percent of females produce 1 broods (litters, clutches) in an average year

40.00 percent of females produce 2 broods (litters, clutches) in an average year

of those females producing progeny, ...

15.00 percent of females produce 1 progeny in an average year

40.00 percent of females produce 2 progeny in an average year

45.00 percent of females produce 3 progeny in an average year 
$\%$ mortality of females between ages $\odot$ and $1=65$

EV in \% mortality: SD $=15$

$\%$ mortality of adult females $(1<=$ age $<=4)=40$

EV in \% mortality: $S D=15$

$\%$ mortality of males between ages $\odot$ and $1=65$

EV in \% mortality: SD $=15$

$\%$ mortality of adult males $(1<=$ age $<=4)=40$

EV in \% mortality: SD $=15$

EVs may be adjusted to closest values possible for binomial distribution.

Initial size of MM:

(set to reflect stable age distribution)

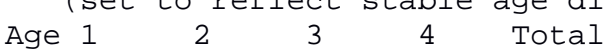

$\begin{array}{llllll}5 & 3 & 1 & 1 & 10 & \text { Males }\end{array}$

Carrying capacity $=20$

with a $\odot .461$ percent increase for $\odot$ years.

$\mathrm{EV}$ in Carrying capacity $=0$

Population 12: KR

Polygynous mating;

$\%$ of adult males in the breeding pool $=37.6$

$\%$ adult females breeding $=100$

EV in \% adult females breeding: SD $=45$

Distribution of number of separately sired broods produced by a female in a year ...

$\odot, \odot \odot$ percent of females produce $\odot$ broods (litters, clutches) in an average year

60.00 percent of females produce 1 broods (litters, clutches) in an average year

40.00 percent of females produce 2 broods (litters, clutches) in an average year

of those females producing progeny, ...

15.00 percent of females produce 1 progeny in an average year

40.0๑ percent of females produce 2 progeny in an average year

45.00 percent of females produce 3 progeny in an average year

$\%$ mortality of females between ages $\odot$ and $1=65$

EV in \% mortality: SD $=15$

$\%$ mortality of adult females $(1<=$ age $<=4)=40$

EV in \% mortality: SD $=15$

$\%$ mortality of males between ages $\odot$ and $1=65$

EV in \% mortality: SD $=15$

$\%$ mortality of adult males $(1<=$ age $<=4)=4 \odot$

EV in \% mortality: SD $=15$

EVs may be adjusted to closest values possible for binomial distribution. 
Initial size of KR:

(set to reflect stable age distribution)

Age 12

$\begin{array}{llllll}15 & 8 & 5 & 2 & 30 & \text { Males }\end{array}$

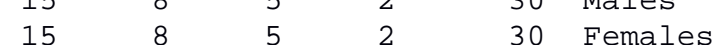

Carrying capacity $=60$

with a $\odot .461$ percent increase for $\odot$ years.

EV in Carrying capacity $=0$

Population 13: SV

Polygynous mating;

$\%$ of adult males in the breeding pool $=37.6$

$\%$ adult females breeding $=100$

$\mathrm{EV}$ in \% adult females breeding: $\mathrm{SD}=45$

Distribution of number of separately sired broods produced by a female in a year ... $\odot .0 \odot$ percent of females produce $\odot$ broods (litters, clutches) in an average year

60.00 percent of females produce 1 broods (litters, clutches) in an average year

$40.0 \odot$ percent of females produce 2 broods (litters, clutches) in an average year

of those females producing progeny, ...

15.00 percent of females produce 1 progeny in an average year

40.00 percent of females produce 2 progeny in an average year

45. 00 percent of females produce 3 progeny in an average year

$\%$ mortality of females between ages $\odot$ and $1=65$

EV in \% mortality: SD $=15$

$\%$ mortality of adult females $(1<=$ age $<=4)=40$

$\mathrm{EV}$ in \% mortality: $\mathrm{SD}=15$

$\%$ mortality of males between ages $\odot$ and $1=65$

EV in \% mortality: SD $=15$

$\%$ mortality of adult males $(1<=$ age $<=4)=40$

$\mathrm{EV}$ in \% mortality: $\mathrm{SD}=15$

EVs may be adjusted to closest values possible for binomial distribution.

Initial size of SV:

(set to reflect stable age distribution)

Age 1 ( 30 age dist

$\begin{array}{lllll}5 & 3 & 1 & 1 & 10 \\ 5 & 3 & 1 & 1 & 10\end{array}$

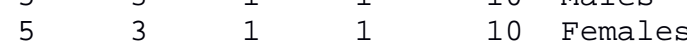

Carrying capacity $=20$

with a $\odot .461$ percent increase for $\odot$ years.

$\mathrm{EV}$ in Carrying capacity $=0$ 
Population 14: NV

Polygynous mating:

$\%$ of adult males in the breeding pool $=37.6$

$\%$ adult females breeding $=100$

$\mathrm{EV}$ in \% adult females breeding: $\mathrm{SD}=45$

Distribution of number of separately sired broods produced by a female in a year...

$\odot .00$ percent of females produce $\odot$ broods (litters, clutches) in an average year

60.00 percent of females produce 1 broods (litters, clutches) in an average year

4๑. $\odot \odot$ percent of females produce 2 broods (litters, clutches) in an average year

of those females producing progeny, ...

15.00 percent of females produce 1 progeny in an average year

$40.0 \odot$ percent of females produce 2 progeny in an average year

45.00 percent of females produce 3 progeny in an average year

$\%$ mortality of females between ages $\odot$ and $1=65$

$\mathrm{EV}$ in \% mortality: $\mathrm{SD}=15$

$\%$ mortality of adult females $(1<=$ age $<=4)=40$

EV in \% mortality: SD $=15$

$\%$ mortality of males between ages $\odot$ and $1=65$

EV in \% mortality: SD = 15

$\%$ mortality of adult males $(1<=$ age $<=4)=40$

EV in \% mortality: $\mathrm{SD}=15$

EVs may be adjusted to closest values possible for binomial distribution.

Initial size of NV:

(set to reflect stable age distribution)

Age 1

$\begin{array}{ccccc}5 & 3 & 3 & 4 & \text { Total } \\ 5 & 3 & 1 & 1 & 10 \text { Males }\end{array}$

$\begin{array}{llllll}5 & 3 & 1 & 1 & 10 & \text { Females }\end{array}$

Carrying capacity $=20$

with a $\odot .461$ percent increase for $\odot$ years.

$\mathrm{EV}$ in Carrying capacity $=0$

Population 15: NNP

Polygynous mating;

$\%$ of adult males in the breeding pool $=37.6$

$\%$ adult females breeding $=100$

$\mathrm{EV}$ in \% adult females breeding: $\mathrm{SD}=45$ 
Distribution of number of separately sired broods produced by a female in a year...

$\odot .0 \odot$ percent of females produce $\odot$ broods (litters, clutches) in an average year

60.00 percent of females produce 1 broods (litters, clutches) in an average year

40.00 percent of females produce 2 broods (litters, clutches) in an average year

of those females producing progeny, ...

15.00 percent of females produce 1 progeny in an average year

40. $0 \odot$ percent of females produce 2 progeny in an average year

45.00 percent of females produce 3 progeny in an average year

$\%$ mortality of females between ages $\odot$ and $1=65$

EV in \% mortality: SD = 15

$\%$ mortality of adult females $(1<=$ age $<=4)=40$

EV in \% mortality: $S D=15$

$\%$ mortality of males between ages $\odot$ and $1=65$

EV in \% mortality: SD $=15$

$\%$ mortality of adult males $(1<=$ age $<=4)=40$

$\mathrm{EV}$ in \% mortality: $\mathrm{SD}=15$

EVs may be adjusted to closest values possible for binomial distribution.

Initial size of NNP:

520

(set to reflect stable age distribution)

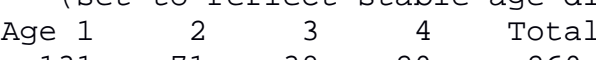

$\begin{array}{llllll}131 & 71 & 38 & 20 & 260 & \text { Males }\end{array}$

$\begin{array}{llllll}131 & 71 & 38 & 20 & 260 & \text { Females }\end{array}$

Carrying capacity $=520$

with a $\odot .461$ percent increase for $\odot$ years.

$\mathrm{EV}$ in Carrying capacity $=\odot$

Population 16: UMMHFR

Polygynous mating;

$\%$ of adult males in the breeding pool $=37.6$

$\%$ adult females breeding $=100$

$\mathrm{EV}$ in \% adult females breeding: $\mathrm{SD}=45$

Distribution of number of separately sired broods produced by a female in a year...

$\odot .0 \odot$ percent of females produce $\odot$ broods (litters, clutches) in an average year

60.00 percent of females produce 1 broods (litters, clutches) in an average year

40.00 percent of females produce 2 broods (litters, clutches) in an average year

of those females producing progeny, ...

15.00 percent of females produce 1 progeny in an average year

40.00 percent of females produce 2 progeny in an average year

45.00 percent of females produce 3 progeny in an average year 
$\%$ mortality of females between ages $\odot$ and $1=65$

EV in \% mortality: SD $=15$

$\%$ mortality of adult females $(1<=$ age $<=4)=40$

EV in \% mortality: SD $=15$

$\%$ mortality of males between ages $\odot$ and $1=65$

EV in \% mortality: SD $=15$

$\%$ mortality of adult males $(1<=$ age $<=4)=40$

EV in \% mortality: SD $=15$

EVs may be adjusted to closest values possible for binomial distribution.

Initial size of UMMHFR:

(set to reflect stable age distribution)

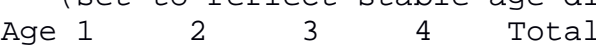

$\begin{array}{llllll}20 & 11 & 6 & 3 & 40 & \text { Males }\end{array}$

340 Females

Carrying capacity $=80$

with a 0.461 percent increase for $\odot$ years.

EV in Carrying capacity $=0$

Population 17: SWTH

Polygynous mating;

$\%$ of adult males in the breeding pool $=37.6$

$\%$ adult females breeding $=100$

EV in \% adult females breeding: $S D=45$

Distribution of number of separately sired broods produced by a female in a year ...

$\odot . \odot \odot$ percent of females produce $\odot$ broods (litters, clutches) in an average year

60.00 percent of females produce 1 broods (litters, clutches) in an average year

40.00 percent of females produce 2 broods (litters, clutches) in an average year

of those females producing progeny, ...

15.00 percent of females produce 1 progeny in an average year

40.0๑ percent of females produce 2 progeny in an average year

45.00 percent of females produce 3 progeny in an average year

$\%$ mortality of females between ages $\odot$ and $1=65$

EV in \% mortality: SD $=15$

$\%$ mortality of adult females $(1<=$ age $<=4)=40$

EV in \% mortality: $S D=15$

$\%$ mortality of males between ages $\odot$ and $1=65$

EV in \% mortality: SD $=15$

$\%$ mortality of adult males $(1<=$ age $<=4)=4 \odot$

EV in \% mortality: SD $=15$

EVs may be adjusted to closest values possible for binomial distribution. 
Initial size of SWTH:

(set to reflect stable age distribution)

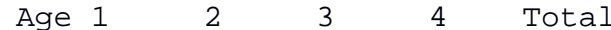

$\begin{array}{llllll}135 & 73 & 39 & 21 & 268 & \text { Males }\end{array}$

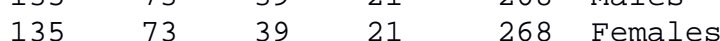

Carrying capacity $=536$

with a 0.461 percent increase for $\odot$ years.

EV in Carrying capacity $=0$

Population 18: NETH

Polygynous mating;

$\%$ of adult males in the breeding pool $=37.6$

$\%$ adult females breeding $=100$

EV in \% adult females breeding: $S D=45$

Distribution of number of separately sired broods produced by a female in a year ... $\odot .0 \odot$ percent of females produce $\odot$ broods (litters, clutches) in an average year

60.00 percent of females produce 1 broods (litters, clutches) in an average year

$40.0 \odot$ percent of females produce 2 broods (litters, clutches) in an average year

of those females producing progeny, ...

15.00 percent of females produce 1 progeny in an average year

40.00 percent of females produce 2 progeny in an average year

45.00 percent of females produce 3 progeny in an average year

$\%$ mortality of females between ages $\odot$ and $1=65$

EV in \% mortality: $S D=15$

$\%$ mortality of adult females $(1<=$ age $<=4)=40$

EV in \% mortality: SD $=15$

$\%$ mortality of males between ages $\odot$ and $1=65$

EV in \% mortality: SD = 15

$\%$ mortality of adult males $(1<=$ age $<=4)=40$

EV in \% mortality: SD $=15$

EVs may be adjusted to closest values possible for binomial distribution.

Initial size of NETH:

240

(set to reflect stable age distribution)

Age $1 \quad 2 \quad 3 \quad 4 \quad$ Total

$\begin{array}{llllc}61 & 32 & 18 & 9 & 120 \\ 61 & 32 & 18 & 9 & 120\end{array}$

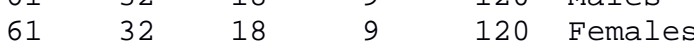

Carrying capacity $=240$

with a $\odot .461$ percent increase for $\odot$ years.

$\mathrm{EV}$ in Carrying capacity $=0$ 
Population 19: $\mathrm{MH}$

Polygynous mating:

$\%$ of adult males in the breeding pool $=37.6$

$\%$ adult females breeding $=100$

$\mathrm{EV}$ in \% adult females breeding: $\mathrm{SD}=45$

Distribution of number of separately sired broods produced by a female in a year...

$\odot .00$ percent of females produce $\odot$ broods (litters, clutches) in an average year

60.00 percent of females produce 1 broods (litters, clutches) in an average year

$40.0 \odot$ percent of females produce 2 broods (litters, clutches) in an average year

of those females producing progeny, ...

15.00 percent of females produce 1 progeny in an average year

40.00 percent of females produce 2 progeny in an average year

45.00 percent of females produce 3 progeny in an average year

$\%$ mortality of females between ages $\odot$ and $1=65$

$\mathrm{EV}$ in \% mortality: $\mathrm{SD}=15$

$\%$ mortality of adult females $(1<=$ age $<=4)=40$

EV in \% mortality: SD $=15$

$\%$ mortality of males between ages $\odot$ and $1=65$

EV in \% mortality: SD = 15

$\%$ mortality of adult males $(1<=$ age $<=4)=40$

EV in \% mortality: $\mathrm{SD}=15$

EVs may be adjusted to closest values possible for binomial distribution.

Initial size of $\mathrm{MH}$ :

100

(set to reflect stable age distribution)

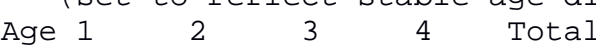

$\begin{array}{lllll}25 & 14 & 7 & 4 & 50 \\ 25 & 14 & 7 & 4 & 50 \text { Males }\end{array}$

$\begin{array}{llllll}25 & 14 & 7 & 4 & 50 & \text { Females }\end{array}$

Carrying capacity $=100$

with a $\odot .461$ percent increase for $\odot$ years.

$\mathrm{EV}$ in Carrying capacity $=0$

Population 20: UNP

Polygynous mating;

$\%$ of adult males in the breeding pool $=37.6$

$\%$ adult females breeding $=100$

$\mathrm{EV}$ in \% adult females breeding: $\mathrm{SD}=45$ 
Distribution of number of separately sired broods produced by a female in a year ...

$\odot .00$ percent of females produce $\odot$ broods (litters, clutches) in an average year

60.00 percent of females produce 1 broods (litters, clutches) in an average year

40.00 percent of females produce 2 broods (litters, clutches) in an average year

of those females producing progeny, ...

15.00 percent of females produce 1 progeny in an average year

40.00 percent of females produce 2 progeny in an average year

45.00 percent of females produce 3 progeny in an average year

$\%$ mortality of females between ages $\odot$ and $1=65$

$\mathrm{EV}$ in \% mortality: $\mathrm{SD}=15$

$\%$ mortality of adult females $(1<=$ age $<=4)=40$

EV in \% mortality: $S D=15$

$\%$ mortality of males between ages $\odot$ and $1=65$

EV in \% mortality: $S D=15$

$\%$ mortality of adult males $(1<=$ age $<=4)=40$

$\mathrm{EV}$ in \% mortality: $\mathrm{SD}=15$

EVs may be adjusted to closest values possible for binomial distribution.

Initial size of UNP:

(set to reflect stable age distribution)

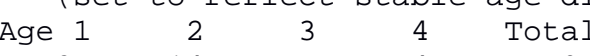

$\begin{array}{lllll}25 & 14 & 7 & 4 & 50 \\ & 14 & 7 & 4 & 50\end{array}$

$\begin{array}{llllll}25 & 14 & 7 & 4 & 50 & \text { Females }\end{array}$

Carrying capacity $=100$

with a $\odot .461$ percent increase for $\odot$ years.

EV in Carrying capacity $=0$ 